d

ANL/ES-CEN-1013

and

FE-1780-2

FE-1780-2

\title{
A DEVELOPMENT PROGRAM ON
}

PRESSURIZED FLUIDIZED-BED COMBUSTION

\section{Quarterly Report}

July 1, 1975-September 30, 1975

by

G. J. Vogel, P. Cunningham, J. Fischer,

B. Hubble, S. Lee, J. Lenc, J. Montagna,

S. Siegel, R. Snyder, S. Saxena,

W. Swift, I. Wilson, and A. A. Jonke

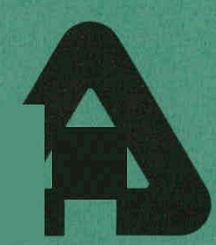

ARGONNE NATIONAL LABORATORY, ARGONNE, ILLINOIS

Operated for the U. S. ENERGY RESEARCH

AND DEVELOPMENT ADMINISTRATION

under Contract W-31-109-Eng-38 DISTRIBUTION OF THIS DOCUMENT. IS UNLIMITED 


\section{DISCLAIMER}

This report was prepared as an account of work sponsored by an agency of the United States Government. Neither the United States Government nor any agency Thereof, nor any of their employees, makes any warranty, express or implied, or assumes any legal liability or responsibility for the accuracy, completeness, or usefulness of any information, apparatus, product, or process disclosed, or represents that its use would not infringe privately owned rights. Reference herein to any specific commercial product, process, or service by trade name, trademark, manufacturer, or otherwise does not necessarily constitute or imply its endorsement, recommendation, or favoring by the United States Government or any agency thereof. The views and opinions of authors expressed herein do not necessarily state or reflect those of the United States Government or any agency thereof. 


\section{DISCLAIMER}

Portions of this document may be illegible in electronic image products. Images are produced from the best available original document. 
The facilities of Argonne National Laboratory are owned by the United States Government. Under the terms of a contract (W-31-109-Eng-38) between the U. S. Energy Research and Development Administration, Argonne Universities Association and The University of Chicago, the University employs the staff and operates the Laboratory in accordance with policies and programs formulated, approved and reviewed by the Association.

\section{MEMBERS OF ARGONNE UNIVERSITIES ASSOCIATION}

The University of Arizona Carnegie-Mellon University Case Western Reserve University The University of Chicago University of Cincinnati Illinois Institute of Technology University of Illinois Indiana University Iowa State University The University of Iowa
Kansas State University The University of Kansas Loyola University Marquette University Michigan State University The University of Michigan University of Minnesota University of Missouri Northwestern University University of Notre Dame
The Ohio State University

Ohio University

The Pennsylvania State University

Purdue University

Saint Louis University

Southern Illinois University

The University of Texas at Austin

Washington University

Wayne State University

The University of Wisconsin

\section{NOTICE}

This report was prepared as an account of work sponsored by the United States Government. Neither the United States nor the United States Energy Research and Development Administration, nor any of their employees, nor any of their contractors, subcontractors, or their employees, makes any warranty, express or implied, or assumes any legal liability or responsibility for the accuracy, completeness or usefulness of any information, apparatus, product or process disclosed, or represents that its use would not infringe privately-owned rights. Mention of commercial products, their manufacturers, or their suppliers in this publication does not imply or connote approval or disapproval of the product by Argonne National Laboratory or the U. S. Energy Research and Development Administration.

Printed in the United States of America

Available from

National Technical Information Service

U. S. Department of Commerce

5285 Port Royal Road

Springfield, Virginia 22161

Price: Printed Copy $\$ 5.50 ;$ Microfiche $\$ 2.25$ 
ANL/ES-CEN-1013

and

FE-1780-2

Coal Conversion and UtilizationDirect Combustion of Coal

(UC-90e)

ARGONNE NATIONAL LABORATORY

9700 South Cass Avenue

Argonne, Illinois 60439

A DEVELOPMENT PROGRAM ON

PRESSURIZED FLUIDIZED-BED COMBUSTION

Quarterly Report

July 1, 1975-September 30, 1975

by

G. J. Voge1, P. Cunningham, J. Fischer, B. Hubble, S. Lee, J. Lenc, J. Montagna, S. Siege1, R. Snyder, S. Saxena, *

W. Swift, I. Wilson, and A. A. Jonke

Chemical Engineering Division

This report was prepared as an account of work The Research and Development Administration, nor any of their employees, not any of their contractors, subcontractors, or their employees, makes any warranty, express or implied, or assumes any legal liability or responsibulty for the accuracy, completeness or usefuiness of any information, apparatus, product or Pringe privately owned rights.

Prepared for the

U. S. Energy Research and Development Administration

under Contract No. 14-32-0001-1780

and the

U. S. Environmental Protection Agency

under Agreement TAS.-D.5-F.hR1

* University of Illinols - Chicago Circle 


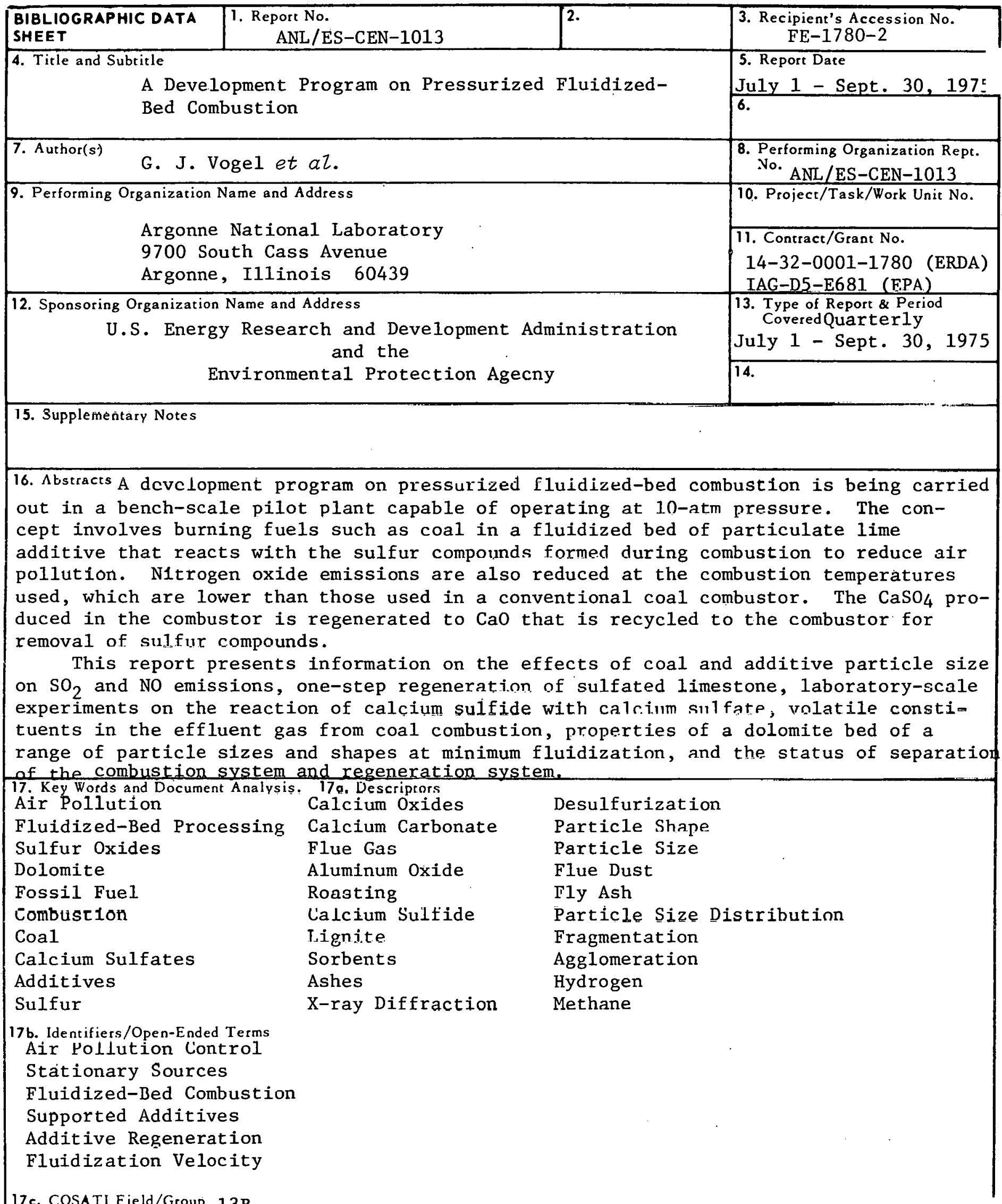

17c. COSATI Field/Group 13B

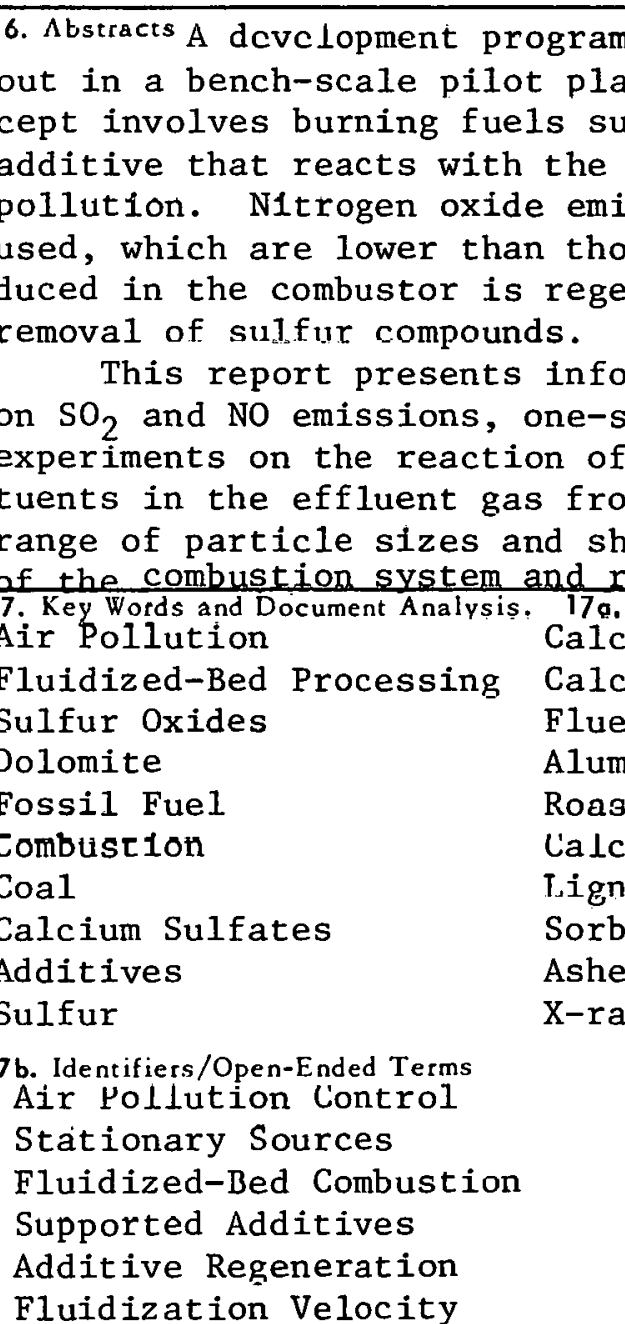

\begin{tabular}{|l|l|l|l|l|}
\hline 18. Availability Statement & 19. Security Class (This & 21. No. of Pages
\end{tabular} 
Summary •. . . . . . . . . . . . . . . . . . . . . 1

Introduction . . . . . . . . . . . . . . . . . 6

Bench-Scale, Pressurized, Fluidized-Bed Combustion Experiments • . 6

Equipment. . . . . . . . . . . . . . . . . 6

Combustion of Lignite in a Fluidized Bed of Alumina. . . . . . 7

Effects of Coal and Additive Particle Sizes. . . . . . . . 8

One-Step Regeneration of Additive. . . . . . . . . . . 16

Sulfation and Regeneration of Supported Additives. . . . . . . . 17

Effect of $\mathrm{SO}_{2}$ Concentration on Sulfation Rate at $900^{\circ} \mathrm{C}$. . . 18

Percent Sulfation of Supported Additive. . . . . . . . 20

Effect of Oxygen Concentration in the Feed Gas on Sulfation

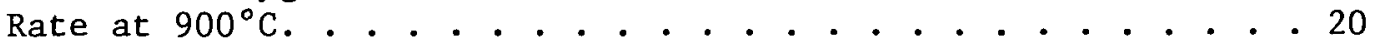

Effect of Temperature on Sulfation Rate. . . . . . . . . . 20

Comparison of Sulfation Rates of Tymochtee Dolomite and

Supported Additive . . . . . . . . . . . . . . . . 21

Regeneration of Sulfated Pellets Using Various Reducing

Gases. . . . . . . . . . . . . . . . . . . 22

Effect of $\mathrm{CO}_{2}$ in Reducing Gas on Regeneration Rate . . . . . . 27

Comparison of Regeneration Rates of Sulfated Pellets and

Sulfated Tymochtee Dolomite. . . . . . . . . . . 28

Cyclic Sulfation-Regeneration Studies. . . . . . . . . . . 29

Sulfur Emission Control Chemistry. . . . . . . . . . . . 33

Coal Combustion Reactions. . . . . . . . . . . . . . . 39

The Determination of Inorganic Constituents in the Effluent

Gas From Coal Combustion . . . . . . . . . . . . . 39

Systematic Study of the Volatility of Trace Elements in

Coal . . . . . . . . . . . . . . . . . . 4 41

Properties of a Dolómite Bed of a Range of Particle Sizes and

Shapes at Minimum Fluilization . . . . . . . . . . . . 4 .

Examination of Earlier Experimental Results. . . . . . . . 42

Properties of Unreacted-Dolomite Bed at Minimum Fluidization . 44

Separation of Combustion and Regeneration Systems . . . . . . . 47

References . . . . . . . . . . . . . . . . . . . 48 


\section{LIST OF FIGURES}

No.

$\underline{\text { Title }}$

Page

1 Bed Temperature and Flue-Gas Composition, Experiment PSI-1R . . . 11

2 Bed Temperature and Flue-Gas Composition, Experiment PSI-2. . . 12

3 Bed Temperature and Flue-Gas Composition, Experiment PSI-3. . . 13

4 Bed Temperature and Flue-Gas Composition, Experiment PSI-4. . . 14

5 Rate of Sulfation of $6.6 \%$, CaO in $\alpha-\mathrm{Al}_{2} \mathrm{O}_{3}$ as a Function of the $\mathrm{SO}_{2}$ Gas Concentration at $900^{\circ} \mathrm{C}$. . . . . . . . . . . . . 19

6 Effect of Oxygen Concentration on the Rate of Sulfation of $6.6 \% \mathrm{CaO}$ in $\alpha-\mathrm{Al}_{2} \mathrm{O}_{3}$ at $900^{\circ} \mathrm{C}$. . . . . . . . . . . . . 21

7 Fffect of Temperature on the Rate of 3utfation of $6.6 \%$ cao in $\alpha-\mathrm{Al}_{2} \mathrm{O}_{3}$ us ing $0.3 \% \mathrm{SO}_{2}-5 \% \mathrm{O}_{2}$. . . . . . . . . . . . 22

8 Comparison of the Rates of Sulfation of Tymochtee Dolomite. and $6.6 \% \mathrm{CaO}$ in $\alpha-\mathrm{Al}_{2} \mathrm{O}_{3}$. . . . . . . . . . . . . . . 23

9 Rate of Regeneration of $\mathrm{CaSO}_{4}$ in $\alpha-\mathrm{Al}_{2} \mathrm{O}_{3}$ using Indicated Concentrations of Carbon Monoxide at $1100^{\circ} \mathrm{C}$. . . . . . . . . 24

10 Rate of Regeneration of $\mathrm{CaSO}_{4}$ in $\alpha-\mathrm{Al}_{2} \mathrm{O}_{3}$ using Indicated Concentrations of Hydrogen at $1100^{\circ} \mathrm{C}$. . . . . . . . . . 25

11 Rate of Regeneration of $\mathrm{CaSO}_{4}$ in $\alpha-\mathrm{Al}_{2} \mathrm{O}_{3}$ using Indicated Concentrations of Methane at $1100^{\circ} \mathrm{C}$. . . . . . . . . . . 26

12 Comparison of the Rate of Regeneration of CaSn $-\alpha-A 1_{2} O_{3}$ and Sulfated Dolomite, using $1 \%$ Methane, Hydrogen, or Carbon Monoxide at $1100^{\circ} \mathrm{C}$. . . . . . . . . . . . . 27

13 Effect of $\mathrm{CO}_{2}$ Concentration in the Reducing Gas on the Rate of Regeneration of Sinlfated $6.6 \% \mathrm{CaO}$ in $\alpha-\Lambda 1_{2} 0_{3}$ at $1100^{\circ} \mathrm{C}$. . . . 29

14 Comparison of the Rate of Regeneration of $\mathrm{CaSO}_{4}-\alpha-\mathrm{Al}_{2} \mathrm{O}_{3}$ and Sulfated Dolomite using $3 \% \mathrm{CH}_{4}, \mathrm{H}_{2}$, or $\mathrm{CO}$ at $1100^{\circ} \mathrm{C}$. . . . 30

15 Comparison of Sulfation Rates in Various Cycles at $900^{\circ} \mathrm{C}$, Using $6.6 \% \mathrm{CaO}$ in $\alpha-\mathrm{Al}_{2} \mathrm{O}_{3}$................ . . 31

16 Comparison of Sulfation Rate in Various Cycles for $6.6 \%$ $\mathrm{CaO}$ in $\alpha-\mathrm{Al}_{2} \mathrm{O}_{3}$ at $900^{\circ} \mathrm{C}$. . . . . . . . . . . . 32

17 Comparison of Regeneration Rates in Various Cycles for $6.6 \%$

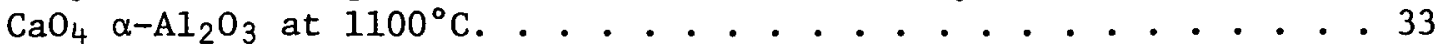




\section{LIST OF FIGURES (Cont'd)}

No.

18 Relationship of $\mathrm{SO}_{2}$ Production and Purge Flow Rate in Solid-Solid Reaction . . . . . . . . . . . . . . . 39

19 Equilibrium for the Equation $3 / 4 \mathrm{CaSO}_{4}+1 / 4 \mathrm{CaS}=\mathrm{CaO}+\mathrm{SO}_{2} 40$ 
№.

$\underline{\text { Title }}$

$\underline{\text { Page }}$

1 Sieve Analyses of Arkwright Coal Size Fractions Used in PSI-Series of Combustion Experiments. . . . . . . . . 8

2 Sieve Analyses of Tymochtee Dolomite Size Fractions Used in PSI-Series of Combustion Experiments . . . . . . . . . 9

3 Operating Conditions and Flue-Gas Analysis for PSI-Series of Combustion Experiments . . . . . . . . . . . . 10

4 Calculated Conversion of $\mathrm{CaO}$ to $\mathrm{CaSO}_{4}$ at $900^{\circ} \mathrm{C}$ and $1000^{\circ} \mathrm{C}$. 20

5 Calculated Regeneration of $\mathrm{CaSO}_{4}$ to $\mathrm{CaO}$. . . . . . . . 27

6 Carbon Content of Pellets After Regeneration with Methane - . 28

7 Completeness of Sulfated and Regeneration in Cyclic Experiment. . . . . . . . . . . . . . . . . 31

8 Summary of TGA and X-Ray Results for Solid-Solid Rcaction

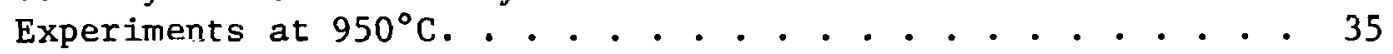

9 Reaction of Calcium Sulfate with Calcium Sulfide in Experiments CAS-10 and CAS-12 . . . . . . . . . . 37

10 Calculations of Mean Sphericity of the Solid Particles, $\bar{\phi}_{S}$, and Correlation of Minimum Fluidization Velocity Data . . : : 43

11 Comparison of the Experimental Values of $\mathrm{u}_{\mathrm{mf}}$ with the Values Calculated Fruñ Eyuation 4. . . . . . . . . . . . . . 44

12 Particle-Size Distribution of Fresh Dolomite Bed Material Before and After the Series C Runs. . . . . . . . . . 45

13 Values of $u_{m f}, L_{m f}, \bar{\varepsilon}_{m f}, R_{p, m f}$, and $\bar{\phi}_{s}$ at Various Temperatures and Pressures. . . . . . . . . . . . . 46 
SUMMARY

Bench-Scale, Pressurized, Fluidized-Bed Combustion Experiments

The 6-in.-dia, pressurized, fluidized-bed combustor was returned to service while work to provide ancillary components for a separate regeneration system contintied. Several unsuccessful attempts were made to complete combustion experiment LIG-2, in which Glenharold 1ignite coal was burned in an inert fluidized bed of alumina. The purpose of this experiment was to examine the sulfur retention capability of lignite ash, which has a high calcium content. Most of the operating problems were minor and were related to returning the combustor to operating status after it had been out of operation for a long period of time. The most serious problem involved the rupture of an internal cooling coil. Examination. of the coil indicated that the coil had been burned through at a point $\sim 14$ in. above the coal feed point. The 48-in.-high standpipe had also been burned off at about the same level. Corrosion did not appear to be a factor in either failure. Failure was probably caused by highly intense and localized hot spots resulting from poor fluidization, as evidenced by erratic $\Delta P$ measurements of bed density and total bed pressure drop and erratic temperature measurements and profiles. The coil and standpipe were replaced.

Further attempts at completing experiment LIG-2 were deferred and four combustion experiments (PSI-series) were completed to measure the effects of coal and additive particle sizc on combustor response variables such as sulfur retention and $\mathrm{NO}_{\mathrm{x}}$ emissions. Arkwright coal with mass-mean particle size levels of $\sim 150 \mu \mathrm{m}$ and $\sim 740 \mu \mathrm{m}$ and Tymochtee dolomite with mass-mean particle size levels of $\sim 370 \mu \mathrm{m}$ and $\sim 740 \mu \mathrm{m}$ were used in the series of experiments ( $2^{2}$ factorial design). The experiments were performed at $843^{\circ} \mathrm{C}\left(1550^{\circ} \mathrm{F}\right), 8 \mathrm{~atm}$, and $\sim 17 \%$ excess combustion air. The calculated gas velocity, designed to be $1.07 \mathrm{~m} / \mathrm{sec}$ $(3.5 \mathrm{ft} / \mathrm{sec})$, ranged from 0.73 to $0.94 \mathrm{~m} / \mathrm{sec}$. Possible explanations for the incongruously low measured gas velocities are (1) unusually poor combustion efficiencies or (2) unmeasured air leaks through the peripheral seals on the rotary valve coal feeder into the coal transport air line.

The level of $\mathrm{SO}_{2}$ in the effluent gas ranged from a low of $160 \mathrm{ppm}$ ( $293 \%$ sulfur retention) in experiment PSI-3 (fine coal, fine additive) to $240 \mathrm{ppm}$ ( $\sim 89 \%$ sulfur retention) in experiment PSI-4 (fine coal, coarse additive). The results indicate a slight increase in sulfur retention with decreasing additive particle size. No significant effect of coal particle size on sulfur retention was observed.

No noticeable effect of coal or additive particle size on No levels in the flue gas ( 120 to $150 \mathrm{ppm}$ ) was observed. Using a recently obtained chemiluminescence andyzer, $\mathrm{NO}_{\mathrm{x}}$ levels of 160 to $210 \mathrm{ppm}$ were rocorded. $\mathrm{NO}_{2}$ levels ( $\mathrm{NO}_{\mathrm{x}}$ leve1 - NO leve1) were $\sim 40$ to $\sim 60 \mathrm{ppm}$, which are considerably higher than the anticipated $\mathrm{NO}_{2}$ levels of 5 to $10 \mathrm{ppm}$. 
Following the completion of the PSI-series of experiments, an additional attempt to complete experiment LIG-2 was unsuccessfully ended when the coal feed line plugged. Subsequently, a crack was discovered at the hairpin section of one of the internal cooling colls. This damaged section will be examined to determine the cause of the failure.

One-Step Regeneration of Additive

Several preliminary reductive decomposition (one-step) regeneration tests have been performed in the 3-in.-dia unit, using partial combustion of coal to supply heat and reducing gases. The major constraint for the existing regenerator, which was not designed for coal feeding, has been found to be its small internal diameter. The volume of air required for transporting coal into the fluidized bed was greater than $50 \%$ of the total fluidizing gas in the regenerator. The transport air jetting into the bed probably caused poor fluidization of the narticles. A thinner refractory lining has been cast in the existing regenerator, enlarging the II to $4.23 \mathrm{ln}$. $(10.8 \mathrm{~cm})$. This should improve fluidization quality.

Sulfated limestone obtained from Pope, Evans, and Robbins (Test 620) was regenerated during the partial combustion of either British coal (Welbeck) or Arkwright coal. During a relatively smooth operating segment of one test (1-hr duration) with welbeck coal, a $\mathrm{SO}_{2}$ concentration of $2.9 \%$ in the wet effluent gas was reached. Bed temperature excursions, followed by partial agglomeration of the sulfated limestone bed, terminated this experiment and some of the other coal-burning test experiments. Because none of these test experiments reached a steady state, no chemical analyses of the products were made.

Sulfation and Regeneration of Supported Additives

Calcium oxide impregnated in $\alpha-\mathrm{Al}_{2} \mathrm{O}_{3}$ is being investigated as an alternative to dolomite and limestone as an additive for lowering the sulfur dioxide level in the off-gas from fluidized-bed coal combustors. In this program, the capability of the supported calcium oxide to react with sulfur dioxide and of the resulting calcium sulfate to be regenerated is being studied experimentally, using thermogravimetric analysi.s.

The $\alpha$-alumina pellets containing $6.6 \%$ calcium oxide by weight were sulfated at $900^{\circ} \mathrm{C}$, using concentrations of sulfur dioxide in the gas stream ranging from $0.05-3 \%$. Calcium utilizations ranged from 74 to $90 \%$, and the time for the reaction to gn to rnmpletion ranged from 4 to $10 \mathrm{hr}$.

The oxygen concentration in the gas phase had only a small effect on the sulfation rate when oxygen was present in stoichiometric excess. However, when sulfur dioxide was in excess, the rate was first order in oxygen concentration. 
The sulfation rate of the pellets increased with temperature up to $900^{\circ} \mathrm{C}$, where it became independent of temperature. Above $900^{\circ} \mathrm{C}$, the reaction is probably diffusion controlled.

Tymochtee dolomite and calcium oxide in $\alpha$-alumina pellets were sulfated under similar experimental conditions to allow comparison. The calcium oxide in $\alpha$-alumina pellets was $95 \%$ sulfated in $6 \mathrm{hr}$ at $900^{\circ} \mathrm{C}$, using $0.3 \%$ sulfur dioxide and excess oxygen, while the dolomite was only $60 \%$ sulfated in $19 \mathrm{hr}$. However, the dolomite contained four times as much calcium as the pellets did.

Sulfated pellets were regenerated using various reducing gases (CO, $\mathrm{H}_{2}$, and $\mathrm{CH}_{4}$ ). In each case, the reaction was 0.8 order in reducing gas concentration. The rate was the same for hydrogen and methane and the rate for carbon monoxide was one third the former rate. The addition of carbon dioxide ( $15 \%$ or more) to the reducing gas lowered the regeneration rate due to the reaction of carbon dioxide with hydrogen to form carbon monoxide. Comparison of other data showed that dolomite was regenerated at a slightly lower rate than was the supported additive; moreover, the product of the reaction when dolomite was regenerated was $50 \% \mathrm{CaO}-50 \% \mathrm{CaS}$ and not $100 \% \mathrm{CaO}$ as with the supported additive.

Ten cyclic sulfation-regeneration reactions were performed on pellets. A substantial decrease in sulfation rate was found during the second cycle. The sulfation rate increased with each succeeding cycle up to cycle 7, where the rate became essentially constant. The rate of regeneration was the same in each cycle in which the same concentration of hydrogen was used.

\section{Sulfur Emission Control Chemistry}

Results are presented on solid-solid regeneration by reaction of $\mathrm{CaS}$ and $\mathrm{CaSO}_{4}$. Yeilds of $\mathrm{CaO}$ as high as $68 \%$ are reported. The results also suggest that higher yields of $\mathrm{CaO}$ occur when the CaS content of the dolomite stones is in excess of the stoichiometric requirement for the reaction.

In other work, two experiments have been performed in which spent dolomite additive from a combustion experiment was reacted with $\mathrm{CaS}$ at $1025^{\circ} \mathrm{C}$ while the effluent gas stream was monitored: the resultant solid products also were analyzed. In one experiment (CAS-10) in which unaltered (only partially calcined) sulfated dolomite was used. the reaction did not proceed well. However, in the other experiment (CAS-12), a gas stream containing $10.5 \% \mathrm{SO}_{2}$ was observed during reaction of fully calcined dolomite particles with CaS. In addition, preliminary estimates of product composition from the CAS-12 experiment indicate that the reaction went to at least $50 \%$ completinn,

Speculation as to the reaction mechanism is also presented. A possible explanation is that the CaS removes the oxygen generated by decomposition of $\mathrm{CaSO}_{4}$, promoting the decomposition reaction. 
Coal Combustion Reactions

The Determination of Inorganic Constituents in the Effluent Gas from Coal Combustion. Some chemical elements carried by combustion gas are known to cause severe metal corrosion. The purpose of this study is to determine quantitatively which elements are present in the hot combustion gas of coal, in either volatile or particulate form, and to differentiate between volatile and particulate species. The identification of the compound form and amount of particulate species and the determination of the amount and form of condensable species are of interest.

The detailed design and the engineering drawing of the laboratoryscale batch unit combustor have been completed. A work project for construction has been set up, and the fabrication specification of the combustor has been written. A design/preliminary safety review of this combustor is being arranged.

Installation of the induction heating unit is continuing. About $95 \%$ of the electrical work has been done.

Systematic Study of the Volatility of Trace Elements in Coal. Knowledge of the vaporization charactcristics of trace elements in coal and the rate of their volatilization is important for combined cycle turbine operation. The objective of this study is to obtain data on the volatility of these elements under practical coal combustion and gasification conditions.

Work has been completed on the electricity and water supplies for the experimental equipment. Setting up of the experimental apparatus is under way.

Properties of a Dolomite Bed of a Range of Particle Sizes and Shapes at M1n1mum F1u1d1zarion

Earlier reported data from a series of seven fluidization experiments with partially sulfated dolomite have been reexamined, and an improved correlation has been presented in the form of Frgun's correlation. The correlation of Wen and Yu (suitably modified) has been tested and found to be less accurate than Ergun's correlation for purposes of predicting minimum fluidization velocities as a function of temperature and pressure.

The minimum fluidization air velocities for a fresh unreacted dolomite bed of a known particle-size distribution over a range of temperature and pressure conditions were determined. These were correlated on the basis of the Ergun relation. Several other relations developed for predicting minimum fluidization velocities were critically examined on the basis of current experimental data. 
Separation of Combustion and Regeneration Systems

As originally installed, the pressurized, fluidized-bed combustor and the regenerator utilized several components in common. Due to the dual function of these components, the two units could not be operated simultaneously.. Modifications, as well as installation of additional equipment, were undertaken to physically separate the two units and permit concurrent investigations of the combustion process and the regeneration process.

Alterations to the combustion system equipment were completed and the system was returned to service. Installation of the new regeneration system is near completion. Preliminary testing of the new system is in progress. The status of the items required to complete installation of the new system is presented. 


\section{INTRODUCTION}

In this program, funded by the Energy Research and Development Administration and the Environmental Protection Agency, fluidized-bed combustion is being studied as a method of removing from the gas phase nearly all atmospheric pollutants (sulfur and nitrogen compounds) generated during the combustion of fossil fuels. The concept involves burning of fuels such as coal in a fluidized bed of particulate lime solids that react with the sulfur compound formed during coal combustion. In another step, the sulfated lime is regenerated for reuse in the combustor.

This quarterly report presents information on pressurized, fluidized-bed combustion experiments intended to measure (1) the effect of calcium in the coal mineral matter on sulfur retention by combusting a high-calcium lignite coa $\perp$ in an inert fluidized bed of alumina, and (2) the effects of coal and additive particle sizes on sulfur retention and $\mathrm{NO}_{\mathbf{x}}$ emissions. Results of preliminary regeneration experiments consisting of in situ combustion of coal in the 3-in.-dia regenerator are described. Studies on the sulfation and regeneration of supported additives, the chemistry of sulfur emission control, coal combustion reactions, properties of a dolomite bed of a range of particle sizes and shapes at minimum fluidization, and separation of the combustion and regeneration systems are also discussed.

\section{BENCH-SCALE, PRESSURIZED, FLUIDIZED-BED COMBUSTION EXPERIMENTS}

'l'he b-in.-dia, pressurized, fluidized-bed combustor was returned to service while work to separate the combustion and regeneration systems (discussed in a following section of this report) continued. Reported here are ( 1 ) attempts to cxamine the sulfur retention capability of $1 \mathrm{~g}-$ nite ash that has a high calcium content by combusting Glenharold lignite coal in an inert fluidized bed of alumina and (2) the preliminary results of four combustion experiments (using Arkwright coal and Tymochtee dolomite) to measure the effects of coal and additive particle size on response variables such as $\mathrm{S}_{2}$ remnval, $\mathrm{N} \mathrm{n}_{\mathrm{X}}$ emissions, and oombuotion efficiency (the latter not reported here).

\section{Equipment}

The major items of the ANL bench-scale equipment are coal and additive feeders, a preheater for the fluidizing gas, a 6-in.-dia fluidizedbed combustor, a 3-in.-dia regenerator, cyclones and filters, and gas sampling and analyzing equipment. The combustor and regenerator are designed for operation at pressures up to $10 \mathrm{~atm}$. The temperatures of the combustor and regenerator are controlled by electrical heaters and cooling coils. The gas analysis system provides on-line measurement of the flue gas components $\mathrm{SO}_{2}$, $\mathrm{NO}, \mathrm{NO}_{\mathrm{x}}, \mathrm{CH}_{4}, \mathrm{CO}_{2}$ and $\mathrm{O}_{2}$ on a continuous basis. The system is thoroughly instrumented and is equipped with an automatic data-logging system. 
Coal and additive are conveyed pneumatically from the feeders to the bottom of the combustor. A nominally constant bed level of 36 in. is maintained in the combustor by use of an overflow pipe.

Combustion of Lignite in a Fluidized Bed of Alumina

Experiment LIG-2 was designed to duplicate all operating conditions but one of a previous combustion experiment, LIG-1. Combustion in LIG-1 had been carried out in a fluidized bed of Tymochtee dolomite with a 1.1 $\mathrm{Ca} / \mathrm{S}$ mole feed ratio whereas LIG-2 was to be carried out in a fluidized bed of alumina.

Sulfur retention for LIG-1 had been $85 \%$, which corresponded to an emission of $\sim 0.21 \mathrm{~b} \mathrm{SO} \mathrm{S}_{2} / 10^{6} \mathrm{Btu}$. It has been proposed, however, that sulfur is retained in the ash when lignite is burned, even at combustion temperatures as high as $1200^{\circ} \mathrm{C}\left(2200^{\circ} \mathrm{F}\right)$. I $^{1}$ If the coal calcium is included in the $\mathrm{Ca} / \mathrm{S}$ mole ratio for experiment $\mathrm{LIG}-1$, the effective $\mathrm{Ca} / \mathrm{S}$ mole ratio could potentially be 3.0. The results of LIG-2 are expected to indicate the relative effectiveness of the calcium in the additive and the calcium in the ash.

Several unsuccessful attempts were made to complete combustion experiment LIG-2. Most of the problems encountered were relatively minor and were related to returning the combustor to service after it had been out of operation for an extended period of time while regeneration experiments were performed. The most serious problem involved the rupture of an Internal cuoling coil. Examination of the coil indicated that the coil had been burned through at a point $\sim 14$ in. above the coal feed point, which is 2 in. above the gas distributor. The 48-in.-high standpipe (an overflow pipe) had also been burned off at about the same level. Preliminary examinations of the burn-through areas gave no indi= cations that corrosion was a factor in the tube failures. The probable cause of failure was localized hot spots caused by poor fluidization, as evidenced by erratic $\Delta \mathrm{P}$ measurements of bed density and total pressure drop across the bed. Measured temperatures were also erratic, indicating poor fluidization. Several large agglomerates of alumina and ash were recovered from the combustor, a further indication of poor fluidization resulting in localized hot spots.

Attempts at completing experiment LIG-2 were temporarily deferred until after the completion of the particle size experiments (PSI-series), the preliminary results of which are presented below.

An additional attempt was subsequently made to complete experiment LIG-2. The attempt was unsuccessful because the coal feed line plugged. Following shutdown of the combustor, a crack was discovered in the hair-. pin section of one of the internal cooling coils. The affected coil has been removed from the combustor and the damaged section of the coil will be examined to determine the cause of failure. 
Effects of Coal and Additive Particle Sizes

Four combustion experiments (PSI-series) were completed to measure the effects of coal and additive particle sizes on combustor response variables such as sulfur retention and $\mathrm{NO}_{\mathbf{x}}$ emissions. The experiments were made in a $2^{2}$ factorial design at two levels each of coal and additive mean particle sizes. Arkwright. coal with mass-mean particle size levels of $\sim 150 \mu \mathrm{m}(-50 \mathrm{mesh})$ and $\sim 640 \mu \mathrm{m}(+50 \mathrm{mesh})$ and Tymochtee dolomite with mass-mean particle size levels of $\sim 370 \mu \mathrm{m}(-30+50$ mesh) and $\sim 740 \mu \mathrm{m}(-14+30$ mesh $)$ were used in the series of experiments.

The as-received Arkwright coal was sieved at a 50-mesh breakpoint which resulted in approximately a 50-50 split by weight and a factor of $\sim 4$ difference in the mass-mean diameters of the two fractions. The Tymochtee dolomite size ranges also resulted in a 50-50 split by weight of the as-received materia1 and a factor of $\sim 2$ difference in the massmean dlameters of the two fractions. The -50 mesh dolomite was remnved from the finer fraction of dolomite to reduce elutriation of bed material from the combustor. Sieve analyocs of the coal and adlitive feed materials are given in Tables 1 and 2, respectively.

Table 1. Sieve Analyses of Arkwright Coal Size Fractions Used in PSI-Series of Combustion Experiments.

\begin{tabular}{|c|c|c|c|c|c|c|}
\hline & \multicolumn{3}{|c|}{ Coarse Material } & \multicolumn{3}{|c|}{ Fine Material } \\
\hline U.S & 3i & eve No. & $\%$ on Sieve & U.S. Sie & eve No. & $\%$ on Sipve \\
\hline & $\begin{array}{l}-14 \\
-20 \\
-30 \\
-45 \\
-50 \\
-80\end{array}$ & $\begin{array}{l}+14 \\
+20 \\
+30 \\
+45 \\
+50 \\
+80\end{array}$ & $\begin{array}{r}0.0 \\
15.2 \\
37.3 \\
37.2 \\
6.4 \\
3.8 \\
0.0 \\
99.9\end{array}$ & $\begin{array}{l}-30 \\
-45 \\
-50 \\
-80 \\
-170 \\
-230 \\
-325\end{array}$ & $\begin{array}{l}+45 \\
+50 \\
+80 \\
+170 \\
+230 \\
+325\end{array}$ & $\begin{array}{r}2.4 \\
3.8 \\
27.1 \\
34.0 \\
10.0 \\
10.0 \\
12.6 \\
99.9\end{array}$ \\
\hline Mass-Mean & Diam & e.ter, $\bar{d}_{\mathrm{m}}$ & $\sim 640 \mu \mathrm{m}$ & & & $150 \mu \mathrm{m}$ \\
\hline Surface-Me & ean D & iameter, $\overline{\mathrm{d}}_{\mathrm{m}}$ & $\sim 560 \mu \mathrm{m}$ & & & $78 \mu \mathrm{m}$ \\
\hline
\end{tabular}

The nominal operating conditions chosen for the series of experi-! ments were a bed temperature of $843^{\circ} \mathrm{C}\left(1550^{\circ} \mathrm{F}\right), 8$ atm pressure, $217 \%$ excess combustion air ( $3 \% \mathrm{O}_{2}$ in dry flue gas), $1.07 \mathrm{~m} / \mathrm{sec}(3.5 \mathrm{ft} / \mathrm{sec})$

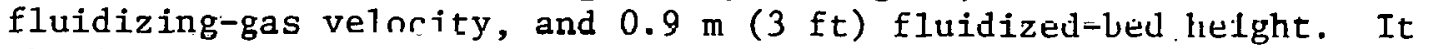
should be indicated here, however, that the fluidizing-gas velocity is not a directly controlled operating variable. Rather, the conditions 
Table 2. Sieve Analyses of Tymochtee Dolomite Size Fractions Used in PSI-Series of Combustion Experiments.

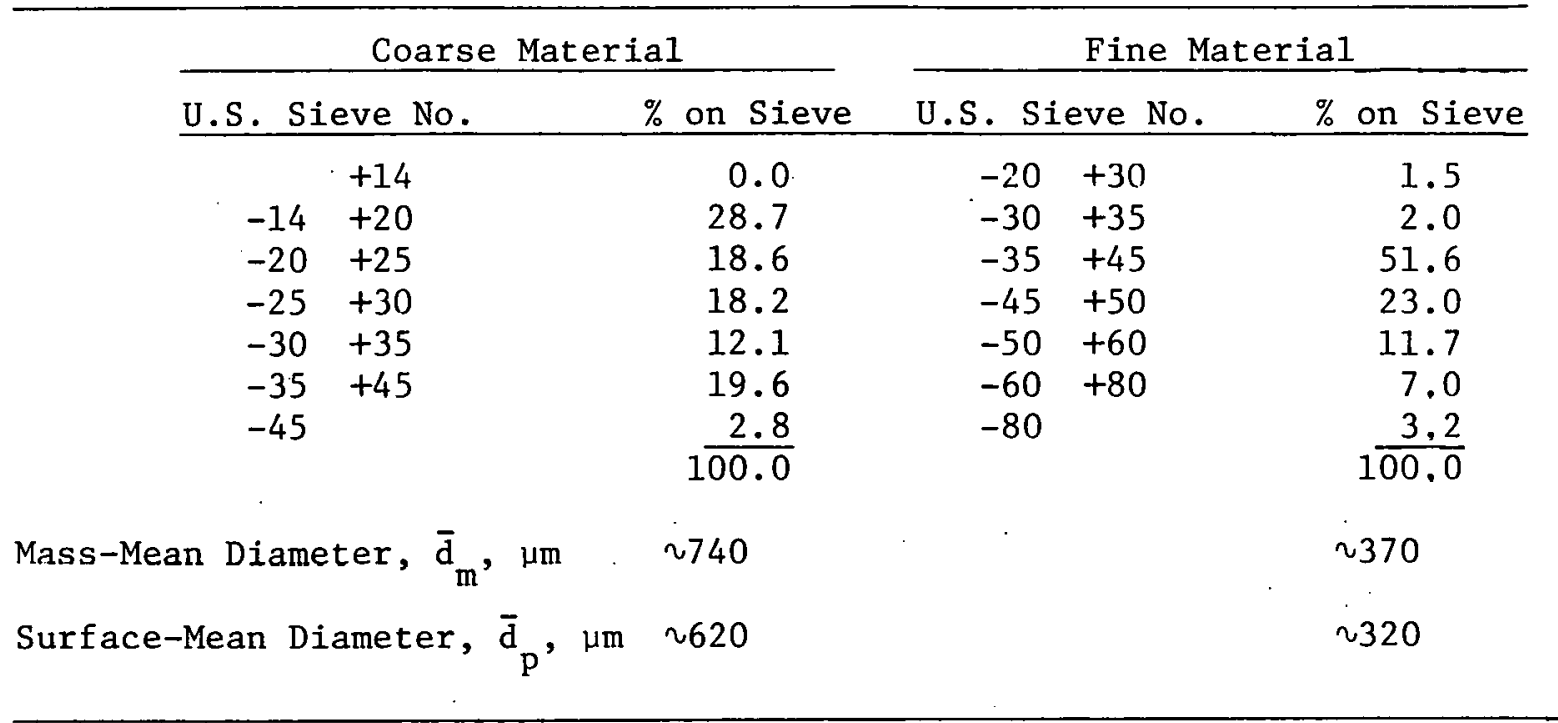

of coal feed rate (in this case, $12.8 \mathrm{~kg} / \mathrm{hr}$ ) and oxygen level in the flue gas $(3 \%)$ are specified as operator-controlled variables. The design velocity of $1.07 \mathrm{~m} / \mathrm{sec}$ theoretically derives from the controlled variables (at $100 \%$ combustion efficiency). The value of $1.07 \mathrm{~m} / \mathrm{sec}$ was selected for this series of experiments to prevent elutriation of large amounts of bed lliaterial, particularly in the cxpcriments with the finer size fractions of dolomite. The actual operating conditions and flue gas analyses for the four combustion experiments are summarized in Table 3. The bed temperature and flue gas analysis data for the four experiments are plotted in Figs. 1 to 4.

The level of $\mathrm{SO}_{2}$ in the flue gas ranged from a low of $160 \mathrm{ppm}$ in experiment PSI-3 (fine coal, fine additive) to $240 \mathrm{ppm}$ in experiment PSI-4 (fine coal, coarse additive). These correspond to sulfur retentions of $\sim 93$ and $\sim 89 \%$, respectively. The observed levels of $\mathrm{SO}_{2}$ for the four experiments (Table 3 ) indicate a slight increase in sulfur retention when the additive particle mass-mean diameter is reduced from $740 \mu \mathrm{m}$ to $370 \mu \mathrm{m}$. Sulfur retentions were 92 and $93 \%$ with the finer dolomite fraction (PSI-2 and -3) as compared with 90 and $89 \%$ with the coarser fraction (PSI-IR and -4 ).

In terms of the observed $\mathrm{SO}_{2}$ levels for the PSI-series of combustion experiments, the effects of increasing the additive particle size at the low and high levels of coal particle size were $+80 \mathrm{ppm}$ and $+30 \mathrm{ppm}$, respectively. This represents an average effect of increasing the $\mathrm{SO}_{2}$ level in the of $f$-gas by $55 \mathrm{ppm}$ (an average percent increase of $33 \%$ ). Similarly, the effects of increasing the coal particle size at the low and high levels of additive particle size were +20 and $-30 \mathrm{ppm}$, respectively. This represents an average effect of decreasing the $\mathrm{SO}_{2}$ level in the off-gas by only $5 \mathrm{ppm}$, an insignificant amount. 
Table 3. Operating Conditions and F-ue-Gas Analysis for PSI-Series of Jombustion Experiments

$\begin{array}{lll}\text { Conbustor: } & \text { ANL }, 6-\text { in. d } & \text { Fluidized-Bed Height: } 0.9 \mathrm{~m}(3 \mathrm{ft}) \\ \text { Bed Temp: } & 843^{\circ} \mathrm{C}\left(1550^{\circ} \mathrm{F}\right) & \text { Excess Air: } \sim 17 \% \\ \text { Pressure: } & \& \text { atm abs } & \end{array}$

\begin{tabular}{|c|c|c|c|c|c|c|c|c|c|c|c|}
\hline \multirow[b]{2}{*}{$\begin{array}{l}\text { Exp. } \\
\text { No. }\end{array}$} & \multicolumn{2}{|c|}{ Arkwright Coal } & \multicolumn{2}{|c|}{ Tymochtee Dolomite } & \multirow[b]{2}{*}{$\begin{array}{c}\mathrm{Ca} / \mathrm{S} \\
\text { Mole Ratio }\end{array}$} & \multirow{2}{*}{$\begin{array}{c}\text { Gas } \\
\text { Velocity } \\
\text { m/sec }\end{array}$} & \multicolumn{5}{|c|}{ Avg Flue-Gas Composition. Dry Basis } \\
\hline & $\begin{array}{l}\overline{\mathrm{d}}_{\mathrm{p}}, \\
\mu \mathrm{m}\end{array}$ & $\begin{array}{c}\text { Feed Rate, } \\
\text { kg'hr }\end{array}$ & $\bar{d}_{m},^{a}$ & $\begin{array}{c}\text { Feed Fate, } \\
\text { kg/t.r }\end{array}$ & & & $\underset{\%}{\mathrm{O}_{2}}$, & $\begin{array}{l}\mathrm{SO}_{2}, \\
\text { ppm }\end{array}$ & $\begin{array}{l}\text { No, } \\
\text { ppm }\end{array}$ & $\begin{array}{l}\mathrm{NO}_{\mathrm{X}}, \\
\mathrm{ppm}\end{array}$ & $\begin{array}{l}\mathrm{CO}, \\
\mathrm{ppm}\end{array}$ \\
\hline PSI-1R & 640 & 13.9 & 740 & 3.3 & 1.3 & 0.94 & 2.8 & $\begin{array}{r}210 \\
(90 \%)^{c}\end{array}$ & 120 & 160 & $\star^{\mathrm{b}}$ \\
\hline PSI -2 & 640 & 12.6 & 3.70 & 3.1 & 1.4 & 0.85 & 3.1 & $\begin{array}{c}180 \\
(92 \%)\end{array}$ & 120 & 170 & $\star^{\mathrm{b}}$ \\
\hline PSI-3 & 150 & 12.3 & 370 & 2.8 & 1.3 & 0.73 & 3.1 & $\begin{array}{r}160 \\
(93 \%)^{c}\end{array}$ & 130 & 180 & 62 \\
\hline PSI-4 & 150 & 13.2 & 740 & 3.2 & 1.4 & 0.82 & 3.0 & $\begin{array}{r}240 \\
(89 \%)^{c}\end{array}$ & 150 & 210 & 50 \\
\hline
\end{tabular}

a Mass mean particle diameter.

bAnalyzer inoperative.

${ }^{c}$ Sulfur retention. 


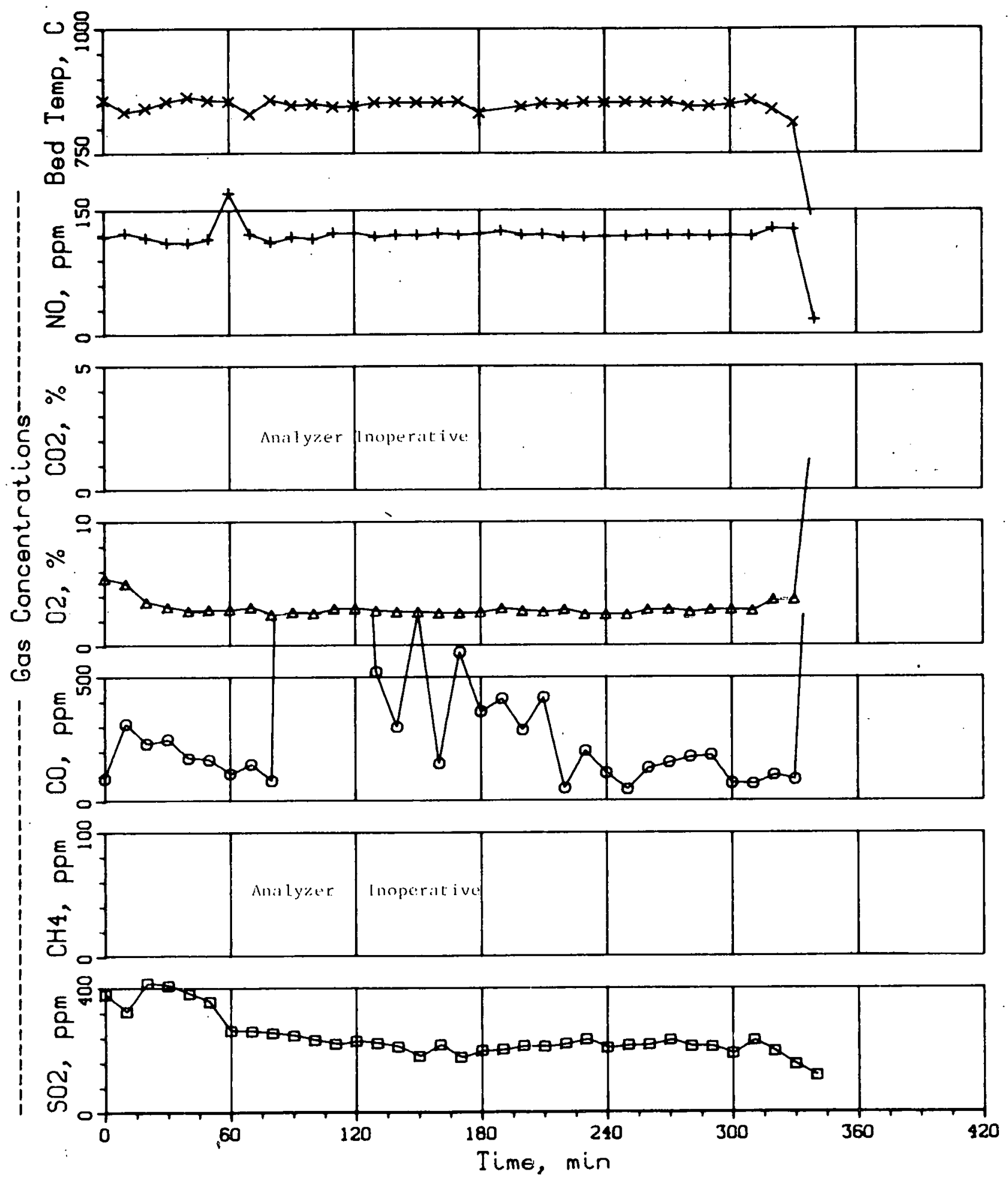

Fig. 1. Bed Temperature and Flue-Gas Composition, Experiment PSI-1R 


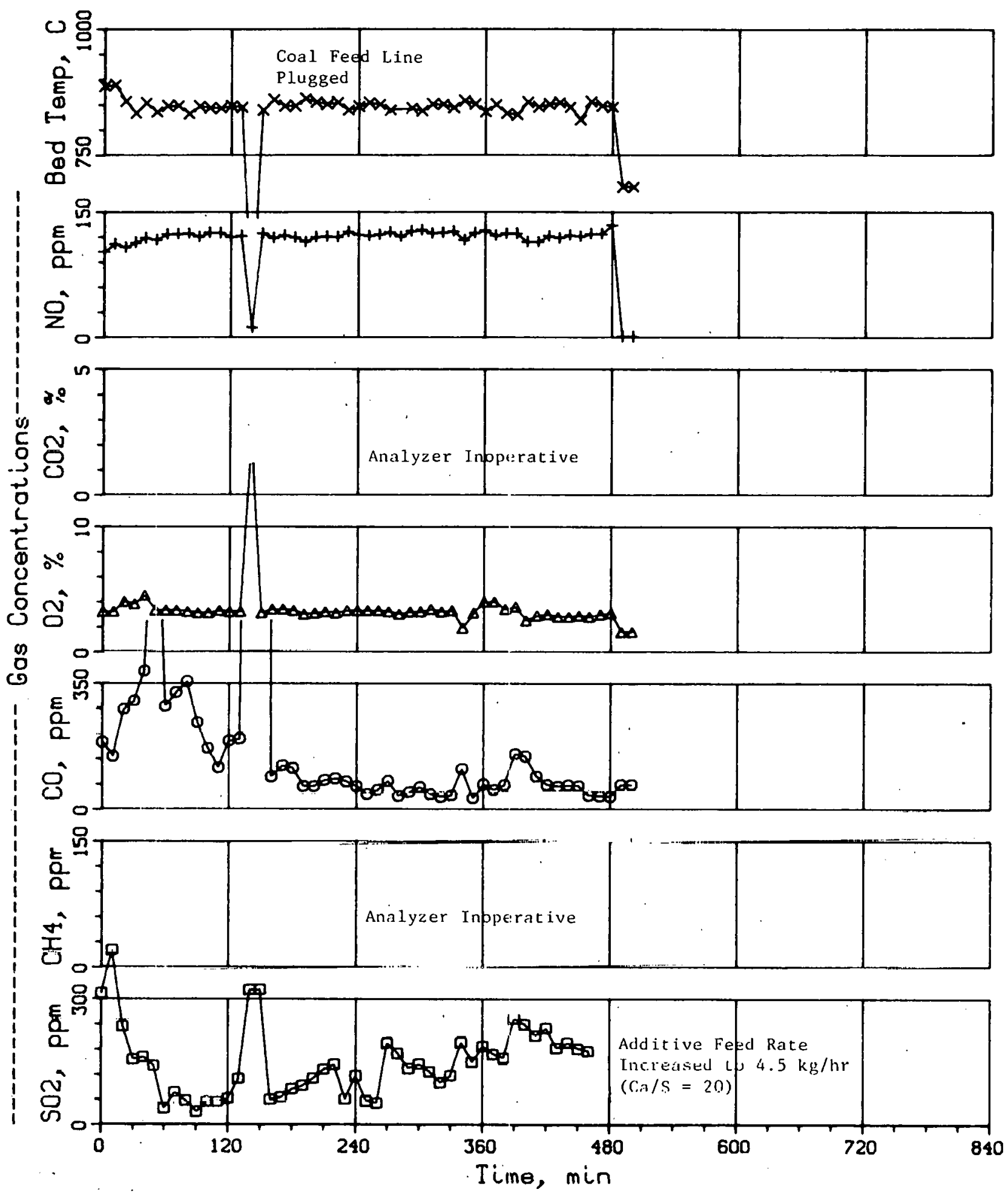

Fig. 2. Bed Temperature and Flue-Gas Composition, Experiment PSI-2 

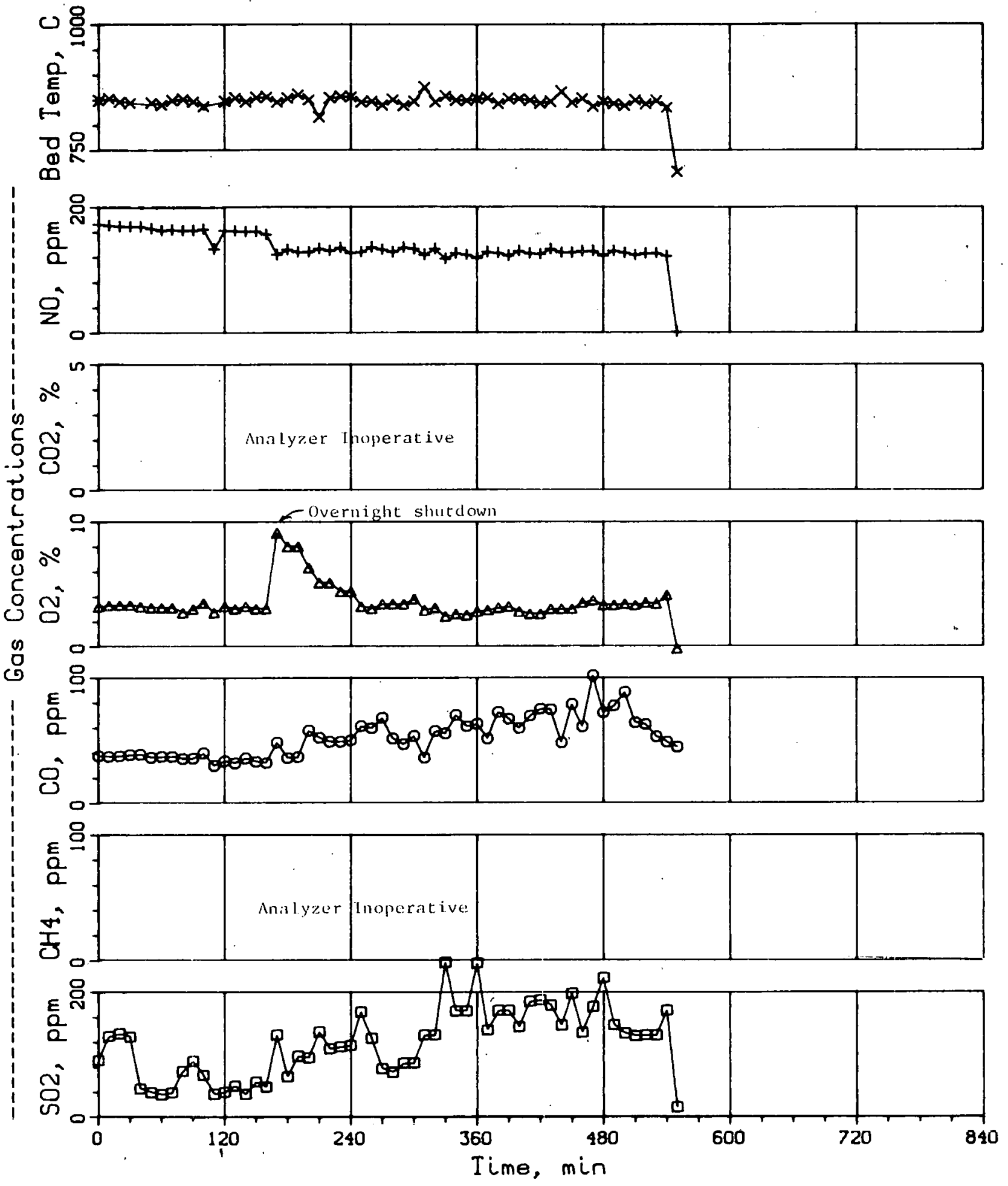

Fig. 3. Bed Temperature and Flue-Gas Composition, Experiment PSI-3 


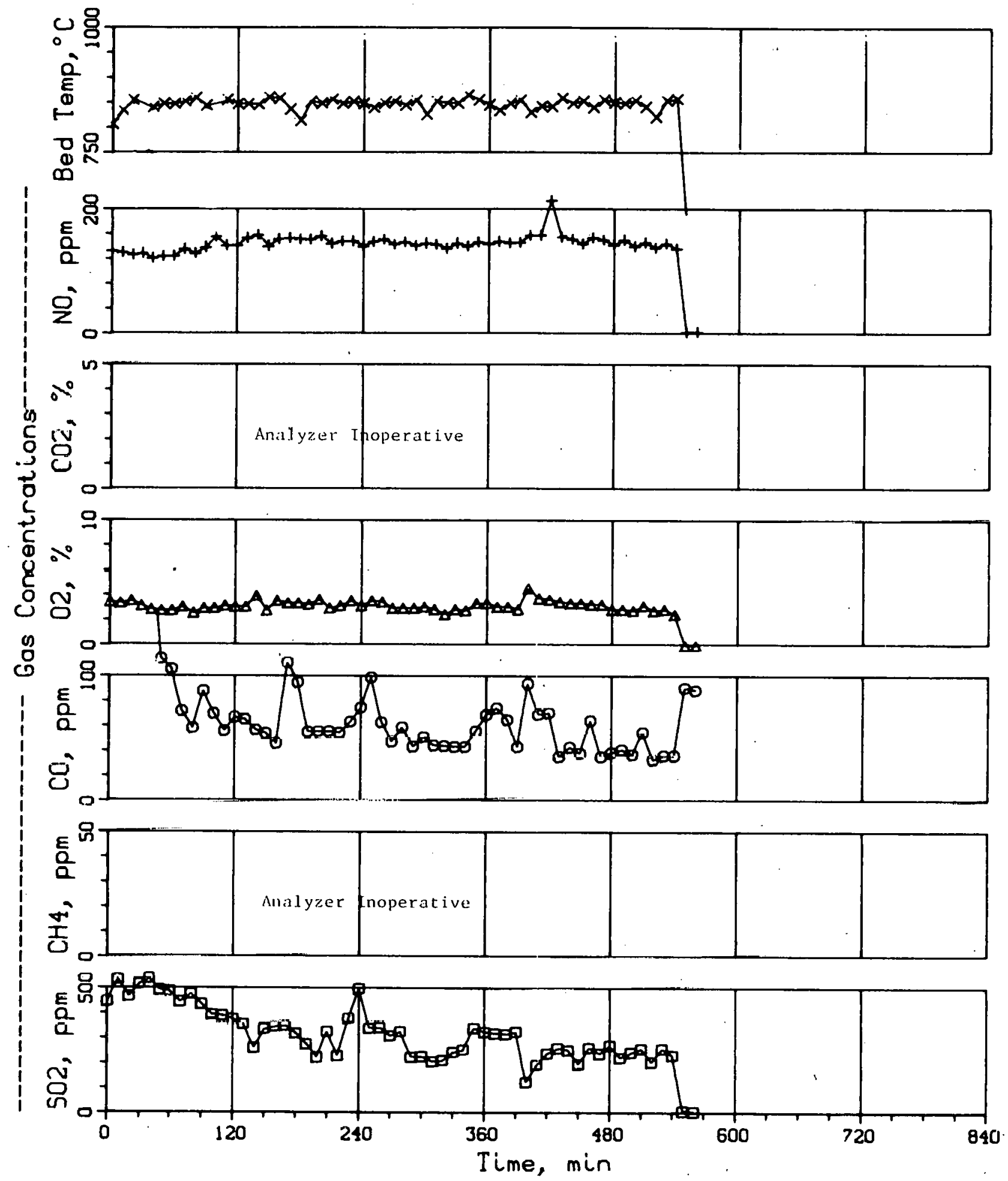

Fig. 4. Bed Temperature and Flue-Gas Composition, Experiment PSI-4 
With the exception of the $\mathrm{SO}_{2}$ level of $240 \mathrm{ppm}$ for experiment PSI-4 (fine coal, coarse additive), the recorded $\mathrm{SO}_{2}$ levels for the PSI experi. ments are considerably lower than the $\mathrm{SO}_{2}$ levels that would be predicted using the correlation of $\mathrm{SO}_{2}$ levels based on the VAR-series of combustion experiments. ${ }^{2}$ The Arkwright coal used in the VAR-series experiments had a mass-mean diameter of $320 \mu \mathrm{m}$ (surface-mean diameter of $120 \mu \mathrm{m}$ ) and the Tymochtee dolomite a mass-mean diameter of $750 \mu \mathrm{m}$ (surface-mean diameter of $560 \mu \mathrm{m})$. Thus, in terms of particle size, experiment PSI-4 corre:sponds most closely with the VAR-series conditions (on the basis of surface-mean diameters). The remaining PSI-series experiments were performed using either finer additive and/or coarser coal as compared with the VAR-series experiments. This is in keeping with the effect indicated above of decreasing additive particle size reducing $\mathrm{SO}_{2}$ levels in the off-gas. While not demonstrated by the PSI-series experiments, there is in the comparison with the VAR-series experiments some indication that increasing coal particle size may also reduce $\mathrm{SO}_{2}$ levels in the flue gas. An effect of coal particle size on $\mathrm{SO}_{2}$ levels may be indirectly related to an expected effect of coal particle size on combustion efficiency ( $i . e$., poorer combustion with larger coal particles release less $\mathrm{SO}_{2}$ and thereby result in apparently better sulfur retention). Further comment on this will be reserved until sufficient analytical work has been completed to determine combustion efficiencies for the PSI-experiments.

In combustion experiments made previously at ANL at atmospheric pressure, ${ }^{3}$ no significant effect of additive particle size on sulfur retention was observed. The earlier experiments were done with Illinois No. 6 coal and limestone No 1359 having average particle sizes of 25 and $100 \mu \mathrm{m}$. Since the observed effect of additive particle size during the PSI-series of combustion experiments was quite small (an average difference of only $55 \mathrm{ppm} \mathrm{SO}_{2}$ ), it is not unreasonable to expect that the effect at even finer sizes of additive could become insignificant.

The levels of NO were quite low for all four combustion experiments, ranging from 120 to $150 \mathrm{ppm}$. Thus, as expected, particle size does not appear to affect No emissions significantly.

By use of a recently installed, on-line chemiluminescence analyzer. it was also possible to obtain values for total $\mathrm{NO}_{\mathbf{x}}$ emissions during the four combustion experiments. Values for $\mathrm{NO}_{\mathrm{x}}$ (see Table 3 ) ranged from 160 to $210 \mathrm{ppm}$, indicating that $\mathrm{NO}_{2}$ levels $\left(\mathrm{NO}_{\mathrm{x}}\right.$ level - NO level) were $\sim 40$, to $\sim 60 \mathrm{ppm}$. These values of $\mathrm{NO}_{2}$ levels are considerably higher than the anticipated levels of 5 to $10 \mathrm{ppm}^{2}$

One aspect of the data reported in Table 3 that is incongruous with the design experimental conditions (and with past experience with the combustor) is the low gas velocities reported for the four combustion experiments. As indicated above, the design operating conditions for this series of experiments (consistent with a coal feed rate of $12.9 \mathrm{~kg} / \mathrm{hr}$ and $17 \%$ excess combustion air) was a gas velocity of $1.07 \mathrm{~m} / \mathrm{sec}(3.5$ $\mathrm{ft} / \mathrm{sec}$ ). Measured gas velocities ranged from $0.73 \mathrm{~m} / \mathrm{sec}$ for experiment 
PSI-3 to $0.94 \mathrm{~m} / \mathrm{sec}$ for experiments PSI-1R. After adjustment for variations from the design coal feed rate of $12.9 \mathrm{~kg} / \mathrm{hr}$, the measured velocities ranged from $\sim 70$ to $\sim 80 \%$, respectively, of the expected velocities of 1.02 to $1.17 \mathrm{~m} / \mathrm{sec}$.

No explanation has been found for this discrepancy in the data, although at least two possibilities exist. One explanation would be unusually poor combustion efficiencies of 70 to $80 \%$ (as compared with 90 to $95 \%$ combustion efficiencies observed in the VAR-series experir ments). Solld samples from the PSI-series are being analyzed for the purpose of making material balance and combustion efficiency calculations.

A second possible explanation pertains to the rotary valve coal feeder. The rotary valve has peripheral seals to which an external air pressure is applied that is approximately equivalent to the system pressure. During maintenance of the valve following sompletinn if the series of experiments, it was found that the peripheral ecalo on the coal feeder were leaking badly. It is thus possible that a large supplemental air flow (unmetered) was introduced through the peripheral seals of the rotary valve into the flow of coal transport air. A rotameter has been installed to measure the air leakage rate.

\section{ONE-STEP REGENERATION OF ADDITIVE}

One of the research goals at ANL is to develop a regeneration process that will regenerate $\mathrm{CaO}$ from additive that has been sulfated during the combustion of coal. A scheme receiving attention is the onestep regeneration of sulfated additive, with in situ combustion of coal yenurating the necessary heat and reducing gases.

The present 3-in,-ID (7.6-r.m) regenerator and ancillary cquipment were not designed for the in sitad combustion of coal. $\Lambda$ ncw atmospheric pressure regenerator with a larger Th is being constructed that will be utilized after the initial phases of this one-step regeneration program are performed with the existing regenerator.

Preliminary test experiments using the in sith comhustion of coal in the $3-i n .-I D ~(7.6-\mathrm{cm})$ regenerator have been performed to evaluate some of the anticipated problems with this regeneration scheme. Sulfated Greer limestone from Pope, Evans, and Robbins (PER), Test 620, was regenerated. The major constraint for the regenerator was that its small internal diameter $(7.6-\mathrm{cm})$ restricts the total amount of fluidizing gas that could be used. The pneumatic transport of coal for feeding into the regenerator required a relatively large amount of transport air. For example, during the test experiments, well over $50 \%$ of the fluidizing gas In the regenerator was coal transport air. This led to poor fluidization because the transport air jets upwards into the bed. 
In all, seven test experiments were attempted to test the coal combustion regeneration scheme. In attempts to reduce the coal transport air required, smaller particle size coal (British coal, -20 mesh) was used. However, bridging in the feed hopper resulted in noncontinuous feeding.

During a smooth feeding segment of one of these tests at $1040^{\circ} \mathrm{C}$ (Coal Burn Test No. 3) with British coal (Welbeck coal) and with the PER sulfated additive fed at $61 \mathrm{~b} / \mathrm{hr}(\sim 2.7 \mathrm{~kg} / \mathrm{hr})$, a $\mathrm{SO}_{2}$ flue gas (wet) concentration of $2.9 \%$ was obtained. The coal feed rate during this test was $\sim 4 \mathrm{lb} / \mathrm{hr}(\sim 1.8 \mathrm{~kg} / \mathrm{hr})$; a large portion $(\sim 50 \%)$ of it did not burn and was recovered in the off-gas cyclone and filters. Temperature excursions followed by bed agglomeration caused termination of this and some of the other test experiments.

The agglomerated sulfated limestone bed material was analyzed by $\mathrm{X}$-ray diffraction; merwinite, $\mathrm{Ca}_{3} \mathrm{Mg}\left(\mathrm{SiO}_{4}\right)_{2}$, was found to be the major constituent. The melting point of this class of materials, which is near $1250^{\circ} \mathrm{C}$, has not yet been measured. Similar material was found in agglomerated sulfated dolomite from the FAC-experiments. ${ }^{4}$ Further experiments using a DTA (differential thermal analyzer) are planned to find the agglomerating reaction temperature at different environmental conditions.

Because the above test experiment (Coal Burn Test No. 3) and other attempted test experiments could not be completed, no chemical analyses of the products were made. The British coal was initially chosen for these tests because of its high ash fusion temperature at reducing conditions (initial deformation temp, $>1100^{\circ} \mathrm{C}$ ). Because of feeding problems with this -20 mesh coal, Arkwright coal ( -14 mesh) was used in later tests to eliminate the bridging of coal in the hopper.

The 3-in.-ID $(7.6-\mathrm{cm})$ regenerator is presently being reworked. To allow recasting of the refractory lining, the inner $8-i n .-d i a ~(20.3-\mathrm{cm})$ pipe has been replaced with a new one. A thinner refractory liner has been cast, and the rebuilt regenerator will have an internal diameter of 4.25 in. $(10.8 \mathrm{~cm})$. This will reduce the ratio of coal transport air to total fluidizing gas in future regeneration experiments. Also, new clamshell type heatere have been installed on the outer wall of the 8-in.-dia $(20.3-\mathrm{cm})$ pipe. The larger regenerator diameter should improve fluidization in the regenerator. These modifications are not expected to be a total solution to bed temperature excursions and/or agglomeration of bed material.

\section{SULFATION $\triangle$ ND REGENERATTNN OF SUPPORTED ADDITIVES}

A research program has been initiated to determine methods of supporting calcium oxide in a highly dispersed state in a matrix of a highstrength, inert material. Calcium oxide is probably more reactive in a dispersed state than is massive $\mathrm{CaO}$; an inert support material would 
supply the strength needed to eliminate the decrepitation problem which probably occurs with dolomite and limestone. In this program, the capability of calcium oxide supported on $\alpha-\mathrm{Al}_{2} \mathrm{O}_{3}$ to react with sulfur dioxide and of the resulting $\mathrm{CaSO}_{4}$ to be regenerated is being studied. The equipment and procedures are described in a previous report. ${ }^{4}$

In this quarterly report, kinetic data are reported on the rate of sulfation of $6.6 \% \mathrm{CaO}-\mathrm{\alpha Al}_{2} \mathrm{O}_{3}$ as a function of temperature and of $\mathrm{SO}_{2}$ and $\mathrm{O}_{2}$ concentrations in the gas phase. Also, a comparison was made of the rate of sulfation of the pellets with that of Tymochtee dolomite. Modeling of the kinetic data was initiated. The rate of regeneration of the sulfated pellets at $1100^{\circ} \mathrm{C}$, using various reducing gases, was determined. Also, the effect of $\mathrm{CO}_{2}$ in the reducing gas on the regeneration rate of the sulfated pellets was measured. Sulfated Tymochtee dolomite was regenerated to allow comparison with the regeneration rate of sulfated pellets. Finally, cyclic sulfation-regeneration experiments were performed.

Effect of $\mathrm{SO}_{2}$ Concentration on Sulfation Rate at $900^{\circ} \mathrm{C}$

Sulfation experiments over a $\mathrm{SO}_{2}$ gas concentration range of 0.05 to $3 \%$ at $900^{\circ} \mathrm{C}$ were performed. Preparation of the gas mixtures for these reactions required the blending of $\mathrm{O}_{2}, \mathrm{SO}_{2}$, and $\mathrm{N}_{2}$ to the various specified concentrations. Mass spectrometric analyses were performed on two blended gas samples to confirm the concentration of each constituent. For gases blended to (1) $0.3 \% \mathrm{SO}_{2}, 5 \% \mathrm{O}_{2}$, and the balance $\mathrm{N}_{2}$ and (2) $0.05 \%$ $\mathrm{SO}_{2}, 5 \% \mathrm{O}_{2}$, and the balance $\mathrm{N}_{2}$, the mass spectrometric results were in good agreement; concentrations were (1) $0.3 \% \mathrm{SO}_{2}, 5.3 \% \mathrm{O}_{2}$ and (2) $0.047 \%$ $\mathrm{SO}_{2}, 5.2 \% \mathrm{O}_{2}$, respectively.

The sulfation kinetic results are shown in Fig. 5 (an earlier version appeared as Fig. 20 of ANL/ES-CEN-1011), where the percent conversion of $\mathrm{CaO}$ in the $\alpha$-alumina pellets to $\mathrm{CaSO}_{4}$ is given as a function of time and $\mathrm{SO}_{2}$ concentration in the gas stream. The results are based on the assump. tion that the $\mathrm{CaO}$ was completely sul.fated. Samples have been submitted for wet chemical analysis to determine the extent of reaction in each experiment. The time required for the reaction to go to completion was 4 to $10 \mathrm{hr}$, depending on the $\mathrm{SO}_{2}$ concentration in the gas stream. Additive residence times will probably be several hours in commercial fluidized beds, and therefore, the rate of sulfation appears to be sufficient.

The order of reaction as a function of $\mathrm{SO}_{2}$ concentration in the gas mixture was found to be 0.7. This is in good agrccment with the 1esulls of 0.76 reported by Yang et $a{ }^{5}{ }^{5}$ They also reported that the rate wns lirst order in $\mathrm{SU}_{2}$ when $\mathrm{H}_{2} \mathrm{O}$ was present. In some future experiments, water will be added to the sulfation gas to determine its effect on sulfation rate. 


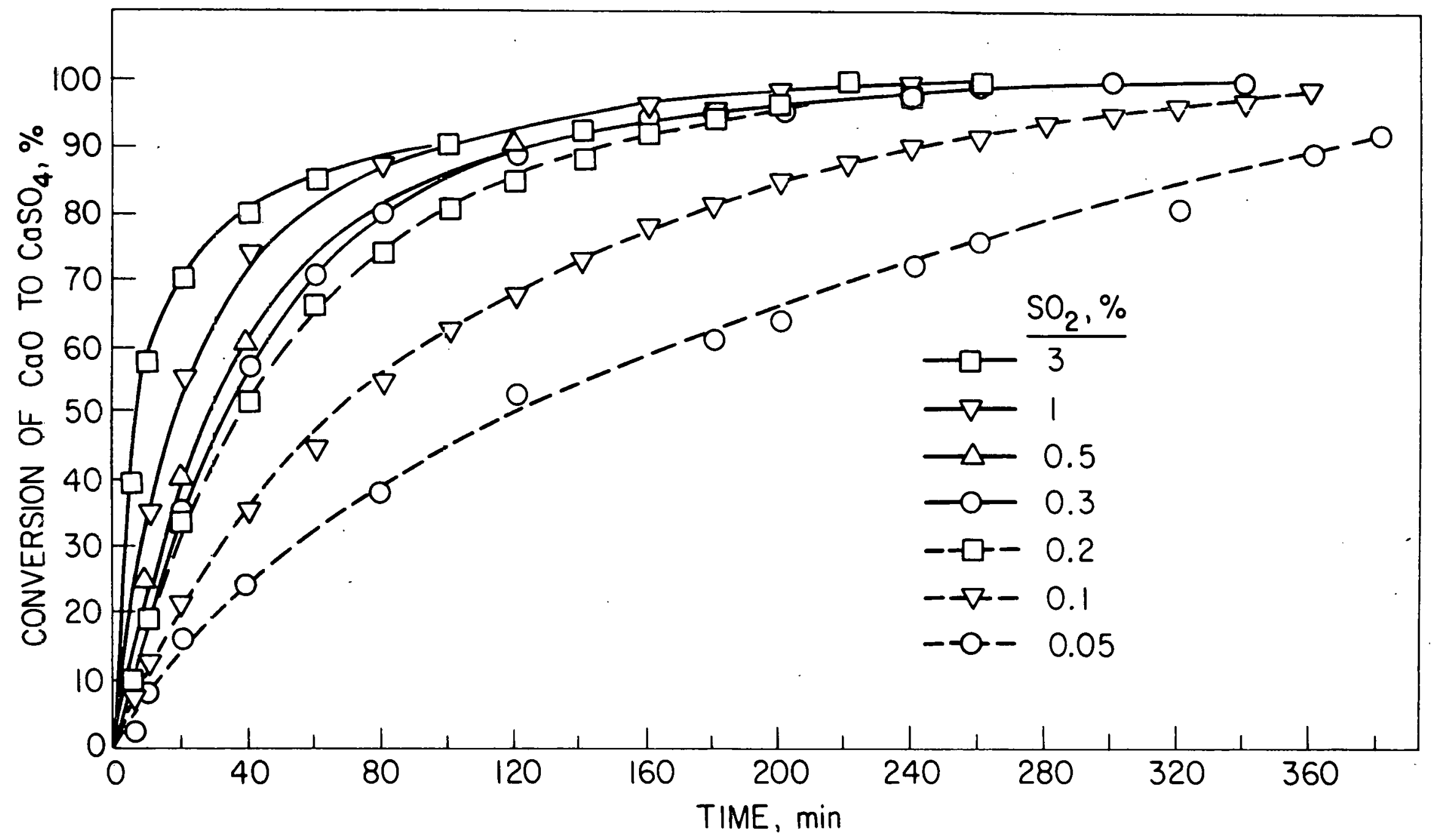

Fig. 5. Rate of Sulfation of $6.6 \% \mathrm{CaO}$ in $\alpha-\mathrm{Al}_{2} \mathrm{O}_{3}$ as a Function of the $\mathrm{SO}_{2}$ Gas Concentration at $900^{\circ} \mathrm{C}$. In all runs, the gas contained $5 \% \mathrm{O}_{2}$ and the balance was nitrogen. 
Percent Sulfation of Supported Additive

In Table 4, the calculated percent conversion of $\mathrm{CaO}$ to $\mathrm{CaSO}_{4}$ is given for the seven sulfation experiments at $900^{\circ} \mathrm{C}$ and one experiment at $1000^{\circ} \mathrm{C}$. The calculations were based on the assumption that the pellets contained 6.64 wt \% CaO (obtained from weight gain during impregnation step) and on the experimental weight gain found from weighing the sample before and after each reaction. Since the calcium concentration varies from sample to sample due to the nonhomogeneity of the pellets, wet chemical analysis will be required to help quantify the kinetic data.

Table 4. Calculated Conversion of $\mathrm{CaO}$ to $\mathrm{CaSO}_{4}$ at $900^{\circ} \mathrm{C}$ and $1000^{\circ} \mathrm{C}$

\begin{tabular}{rccc}
\hline Temp, ${ }^{\circ} \mathrm{C}$ & $\begin{array}{c}\mathrm{SO}_{2} \text { Gas } \\
\text { Concentration, \% }\end{array}$ & Duration & $\begin{array}{c}\text { Sulfation } \\
\text { Completeness, \% }\end{array}$ \\
900 & 3 & $4 \mathrm{hr}$ & 90 \\
900 & 1. & $5 \mathrm{hr}$ & 74 \\
900 & 0.5 & $5 \mathrm{hr}, 20 \mathrm{~min}$ & 78 \\
900 & 0.3 & $6 \mathrm{hr}, 30 \mathrm{~min}$ & 85 \\
900 & 0.2 & $4 \mathrm{hr}, 40 \mathrm{~min}$ & 81 \\
900 & 0.1 & $7 \mathrm{hr}$ & 85 \\
900 & 0.05 & $10 \mathrm{hr}, 10 \mathrm{~min}$ & 74 \\
1000 & 0.3 & $5 \mathrm{hr}, 10 \mathrm{~min}$ & 79 \\
\hline
\end{tabular}

Effect of Oxygen Concentration in the Feed Gas on Sulfation Rate at $900^{\circ} \mathrm{C}$

Experiments have been performed to determine the effect of the $\mathrm{O}_{2}$ concentration on the sulfation rate of pellets. Results for runs at $900^{\circ} \mathrm{C}$ using $0.3 \% \mathrm{SO}_{2}$ mixed with $5 \%$, $0.5 \%$ or $26 \mathrm{ppm} \mathrm{O}_{2}$ (balance is nitrogen) are shown 1n Fig. 6. When oxygen is in excess, the rate is nearly independent of oxygen concentration and is approximately 0.1 order. However, when $\mathrm{SO}_{2}$ is in excess, the rate is first nrier in oxygen concentration. This is consistent with the assumption that $\mathrm{SO}_{2}$ reacts with $\mathrm{O}_{2}$ to form $\mathrm{SO}_{3}$ before reacting with $\mathrm{CaO}$.

$$
\begin{aligned}
& \mathrm{SO}_{2}+1 / 2 \mathrm{O}_{2} \rightarrow \mathrm{SO}_{3} \\
& \mathrm{SO}_{3}+\mathrm{CaO} \rightarrow \mathrm{CaSO}_{4}
\end{aligned}
$$

Effect of Temperature on Sulfation Rate

As shown in Fig. 7 , the rate of sulfation increases with temperature up to $900^{\circ} \mathrm{C}$, where it becomes independent of temperature (within experimental error). The results were reproducible for various $\mathrm{CaO} / \mathrm{SO}_{2}$ ratios and there- 


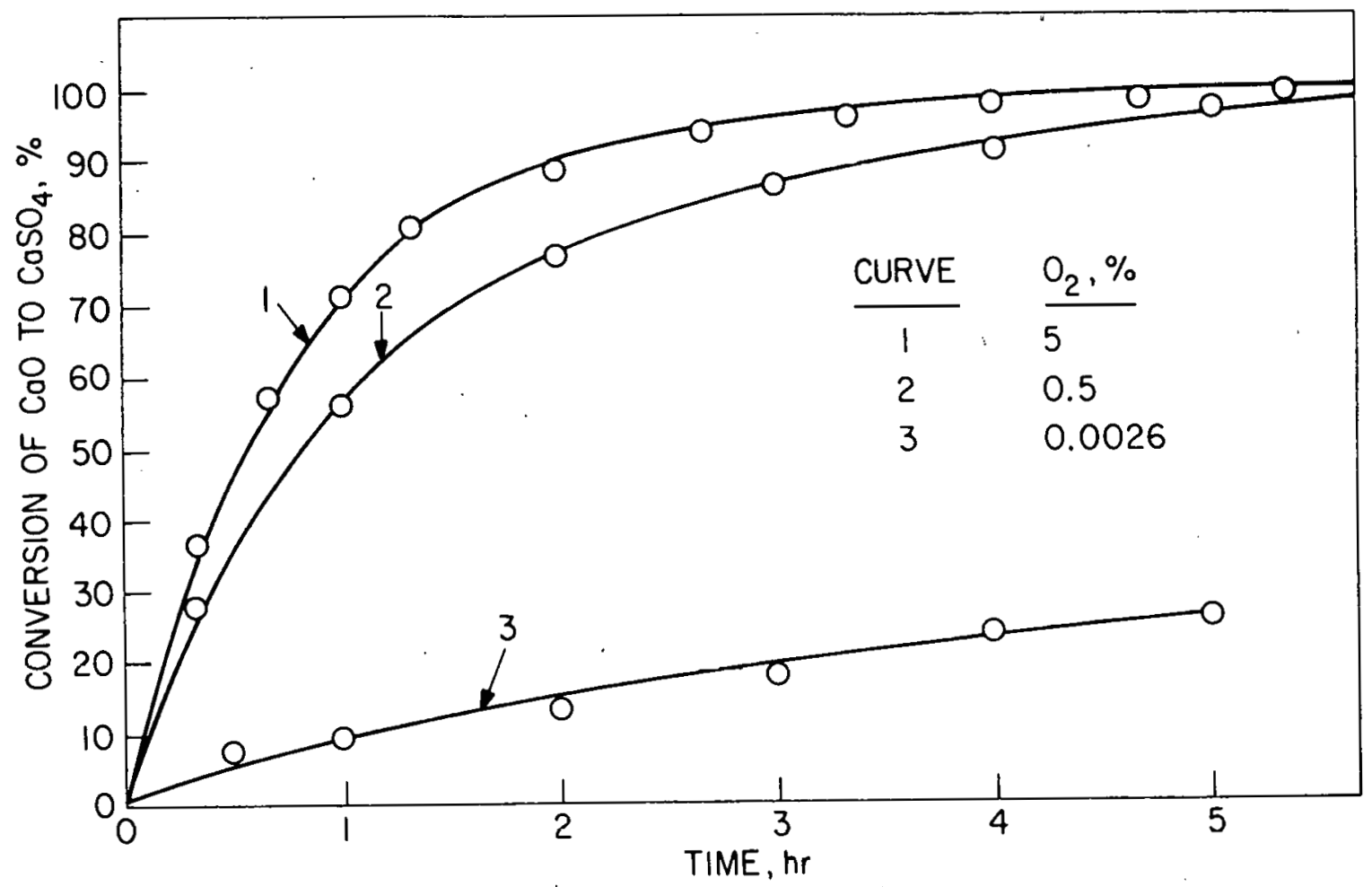

Fig. 6. Effect of Oxygen Concentration on the Rate of Sulfation of $6.6 \% \mathrm{CaO}$ in $\alpha-\mathrm{Al}_{2} \mathrm{O}_{3}$ at $900^{\circ} \mathrm{C}$. Sulfating Gas Mixture; $0.3 \% \mathrm{SO}_{2}$ in $\mathrm{N}_{2}$ plus Indicated Concentration of $\mathrm{O}_{2}$.

fore the sulfation rates were not $\mathrm{SO}_{2}$ limited. The independence of the rate at temperatures above $900^{\circ} \mathrm{C}$ probably indicates that the reaction is diffusion controlled at and above that temperature.

Comparison of Sulfation Rates of Tymochtee Dolomite and Supported Additive

Tymochtee dolomite was sulfated in the TGA unit at $900^{\circ} \mathrm{C}$, using $0.3 \%$ $\mathrm{SO}_{2}-5 \% \mathrm{O}_{2}$ in $\mathrm{N}_{2}$, for comparison with the supported additive (Fig. 8). The information obtained will help in determining the relative effectiveness of the supported additive in reducing $\mathrm{SO}_{2}$ concentrations in the effluent gas from a fluidized-bed combustor. Sulfation of the supported additive was complete in $6 \mathrm{hr}$; sulfation of the Tymochtee dolomite was approximately $60 \%$ complete in $19 \mathrm{hr}$. In an earlier EA-series experiment in the combustor, ${ }^{4}$ approximately $60 \%$ calcium utilization was obtained for Tymochtee dolomite in the fluidized bed, which is in good agreement with the calcium utilization obtained for dolomite in the TGA unit. 


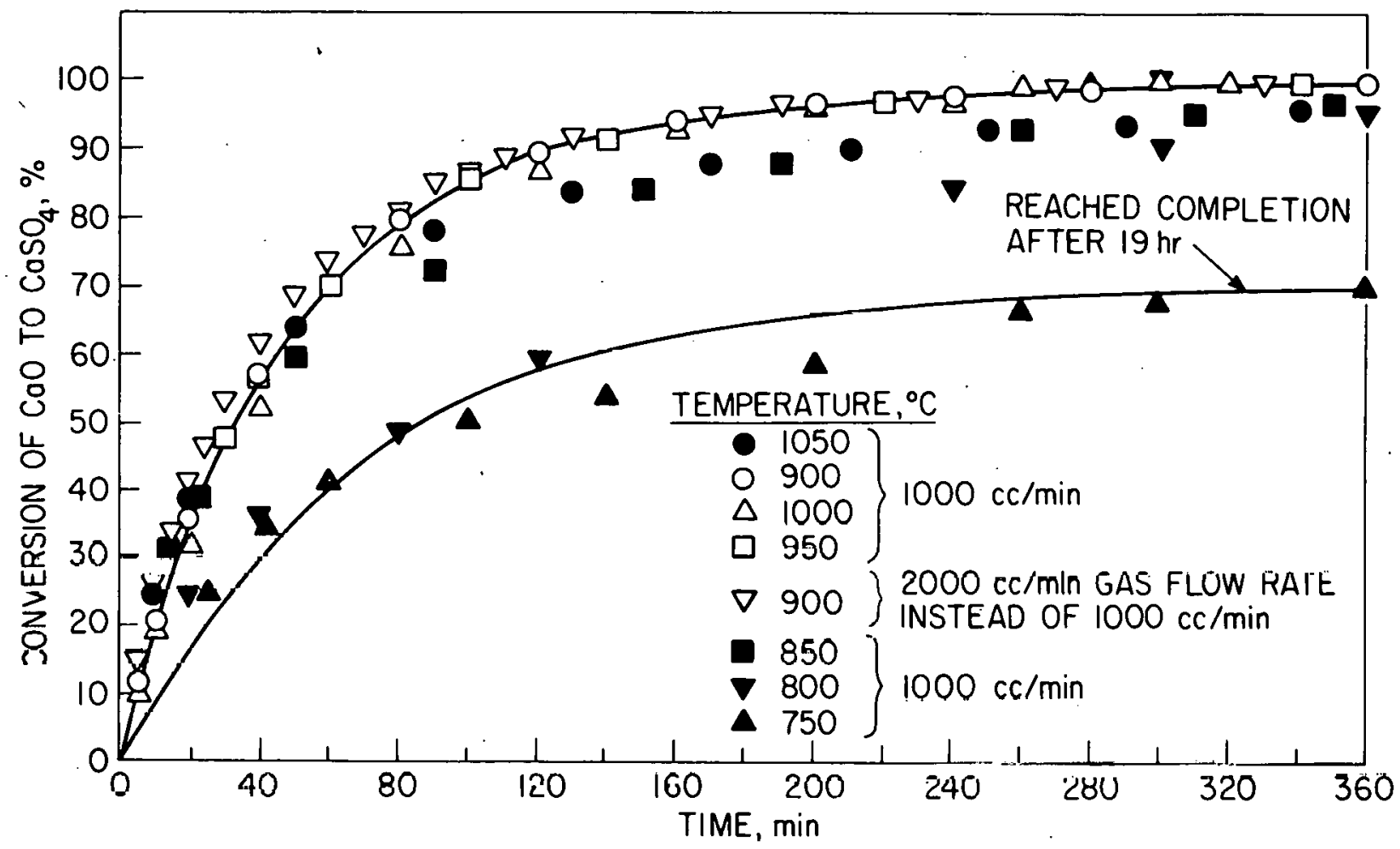

Fig. 7. Effect of Temperature on the Rate of Sulfation of $6.6 \% \mathrm{CaO}$ in $\alpha-\mathrm{Al}_{2} \mathrm{O}_{3}$ using $0.3 \% \mathrm{SO}_{2}-5 \% \mathrm{O}_{2}$

It must be remembered that the dnlnmite containe approurimatcly four times as much calcium as the pellets. Therefore, in $6 \mathrm{hr}$ the dolomite utilized approximately 2.5 times the quantity of calcium utilised by the suppirled additive.

In an earlier VAR-series of combustion experiments, calcium utilization in dolomite in the fluidized bed ranged from 33 to $83 \%$ and was inversely proportional to the $\mathrm{Ca} / \mathrm{S}$ ratin. ${ }^{2}$ The maximum calcium utilization ( $83 \%$ ) was obtained with low $\mathrm{Ca} / \mathrm{S}$ ratios in the VAR-series. By comparisun, the TGA runs were performed with excess $\mathrm{SO}_{2}$ and therefore low $\mathrm{Ca} / \mathrm{S}$ ratios. However, calcium utilization was only $60 \%$ in the TGA runs. Thus, TGA results do not agree with results of the VAR experiments. Possibly, long residence times could account for the high calcium utilization results obtained in the fluidized bed. Also, $\mathrm{H}_{2} \mathrm{O}$ (which should increase the reaction rate) was absent from the TGA sulfation gas.

Regeneration of Sulfated Pellets using Various Reducing Gases

One-step regeneration studies are being performed on sulfated pellets using varlous gas compositions and temperatures. Regeneration experiments using $\mathrm{CO}, \mathrm{H}_{2}$, and $\mathrm{CH}_{4}$ at $1100^{\circ} \mathrm{C}$ are complete. 


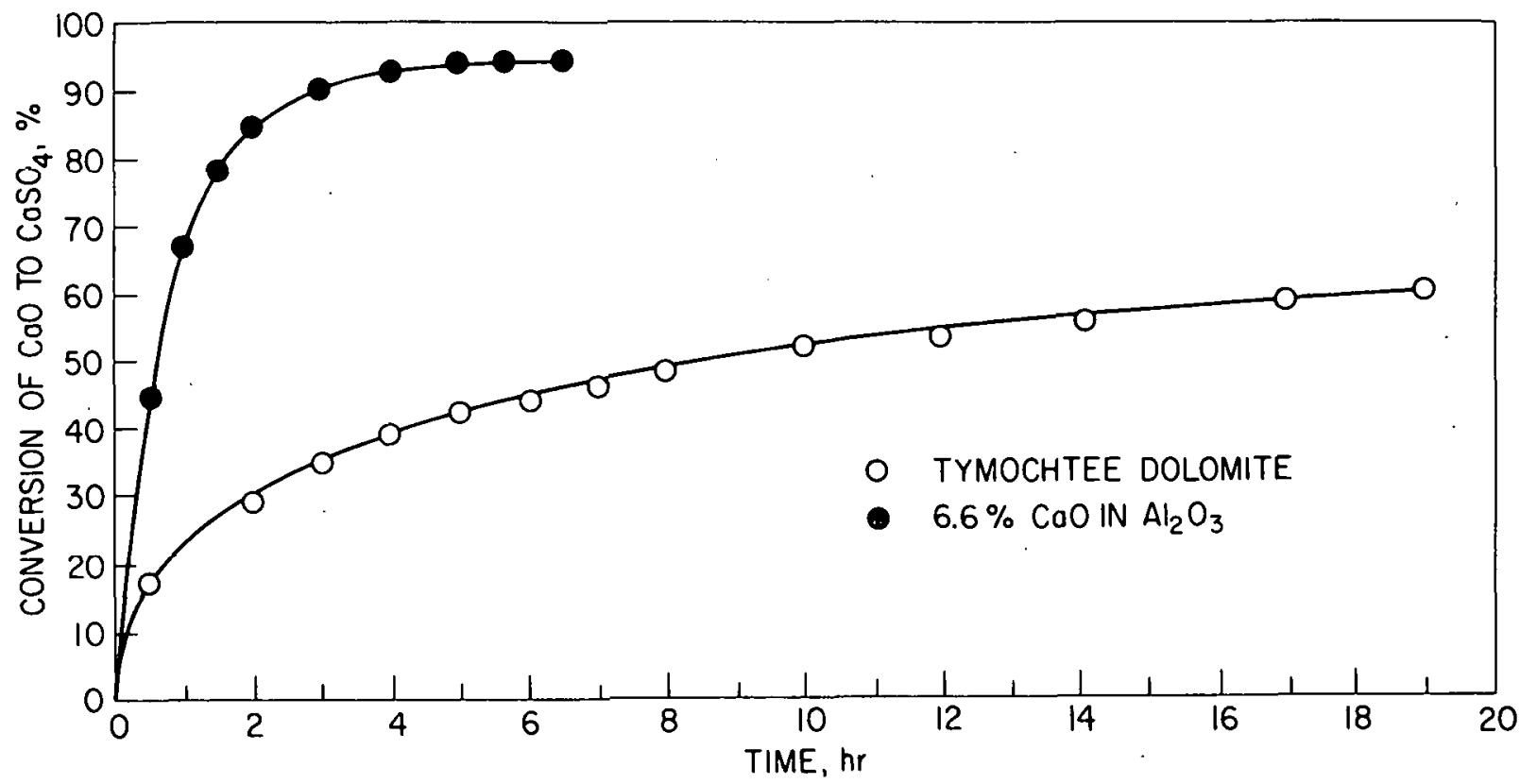

Fig. 8. Comparison of the Rates of Sulfation of Tymochtee Dolomite and $6.6 \% \mathrm{CaO}$ in $\alpha-\mathrm{Al}_{2} \mathrm{O}_{3}$. Sulfation Gas Mixture: $0.3 \% \mathrm{SO}_{2}$ and $5 \% \mathrm{O}_{2}$ in $\mathrm{N}_{2}$. Sulfation Temperature: $900^{\circ} \mathrm{C}$

The regeneration rates at $1100^{\circ} \mathrm{C}$ as a function of reducing gas concentration for $\mathrm{CO}, \mathrm{H}_{2}$, and $\mathrm{CH}_{4}$ are given in Figs. 9, 10, and 11 , respectively. For each reducing gas, the percent reduction of $\mathrm{CaSO}_{4}$ is given as a function of time, for reducing gas concentrations ranging from $0.1 \%$ to $6 \%$. In each case, the reaction is 0.8 order in reducing gas concentration, less that 4 minutes being required for complete regeneration when using a $6 \%$ reducing gas concentration. X-ray diffraction results on the regenerated pellets showed that the product was a mixture of $\mathrm{CaO} \cdot \mathrm{Al}_{2} \mathrm{O}_{3}$ and $\mathrm{CaO} \cdot 2 \mathrm{Al}_{2} \mathrm{O}_{3}$ and that no $\mathrm{CaS}$ or $\mathrm{CaSO}_{4}$ was present. However, when methane was used as a reductant, SEM analysis showed trace amounts of sulfur were present using a scanning electron microscope.

Data plotted in Fig. $9-11$ are based on the assumption of $100 \%$ regeneration of $\mathrm{CaSO}_{4}$ to $\mathrm{CaO}$. This seems reasonable on the basis of weight loss information. Table 5 presents the percent regeneration that occurred for each run, calculated from the experimental weight loss. In the regeneration runs, the experimental weight loss was obtained by weighing the sample before and after each reaction.

A comparison of the rate of regeneration of $\mathrm{CaSO}_{4}$ in $\alpha-\mathrm{Al}_{2} \mathrm{O}_{3}$ and in sulfated dolomite using $\mathrm{CO}, \mathrm{H}_{2}$, and $\mathrm{CH}_{4}$ is given for a $1 \%$ reducing gas concentration in Fig. 12. 


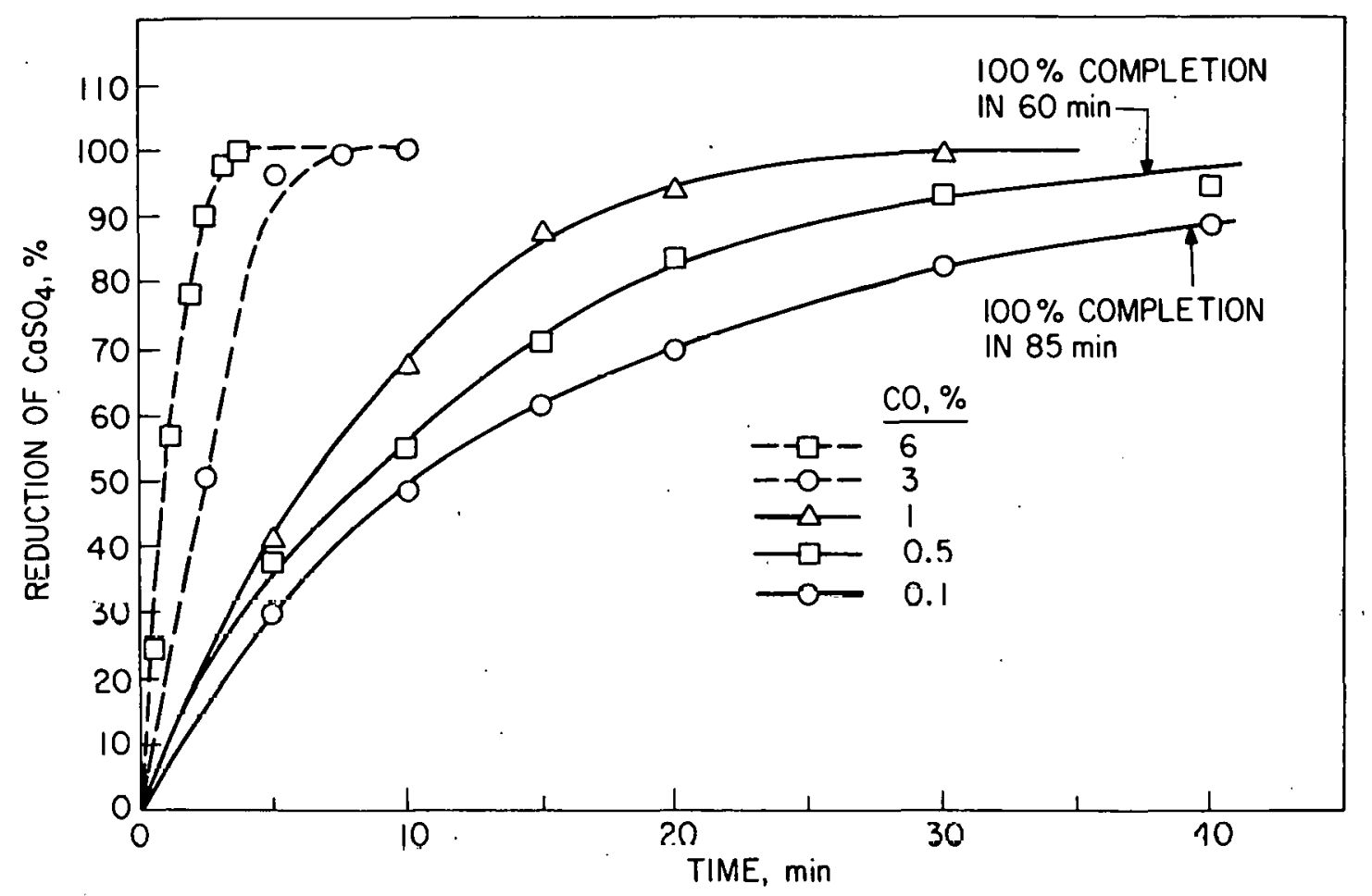

Fig. 9. Rate of Regeneration of $\mathrm{CaSO}_{4}$ in $\alpha-\mathrm{Al}_{2} \mathrm{O}_{3}$. using Indicated Concentrations of Carbon Monoxide (the balance--nitrogen) at $1100^{\circ} \mathrm{C}$.

The rates of regeneration when $\mathrm{CH}_{L}$ and $\mathrm{H}_{3}$ were user are essentially the same, while the regeneration rate when $C O$ was used is lower at each redicing gas concentration. Thermodynamically, the decomposition of $\mathrm{CH}_{4}$ to $\mathrm{C}$ and $\mathrm{H}_{2}$ is favored at $1100^{\circ} \mathrm{C}$. Therefure, il 1 s thought that hydrogen is the actual regeneration gas when $\mathrm{CH}_{4}$ is used, and that the decomposition of $\mathrm{CH}_{4}$ is not rate-limiting. Hence, the same rate of regeneration was obtained using $\mathrm{CH}_{4}$ and $\mathrm{H}_{2}$. Further evidence in support of this idea was found when pellets rediced with methane, hydrogen, or carhnn mnnnxide were sectioned for SFM analysis. The pollcto roduccd with CIT 4 wete black on the interior while those regenerated with $\mathrm{H}_{2}$ or $\mathrm{CO}$ were white. Analysis verifled that carbon deposition occurred when $\mathrm{CH}_{4}$ was used.

Analyses have shown that if $1.3 \mathrm{mg}$ of $\mathrm{C}$ (from the reduction of $\mathrm{CH}_{4}$ to $\mathrm{C}$ and $\mathrm{H}_{2}$ ) was present in each $35 \mathrm{mg}$ pellet, enough $\mathrm{H}_{2}$ would also be produced to reduce all of the $\mathrm{CaSO}_{4}$ to $\mathrm{CaO}$. Table 6 gives the quant1ty of carbon found in the pellets after regeneration at various reducing gas concentrations. The amount of carbon deposition in the pellets is less than that needed to obtain enough hydrogen for complete regeneration of the $\mathrm{CaSO}_{4}$. However, carbon deposition might also have occurred throughout the TGA unit, making available the required amount of hydrogen for regeneration. 


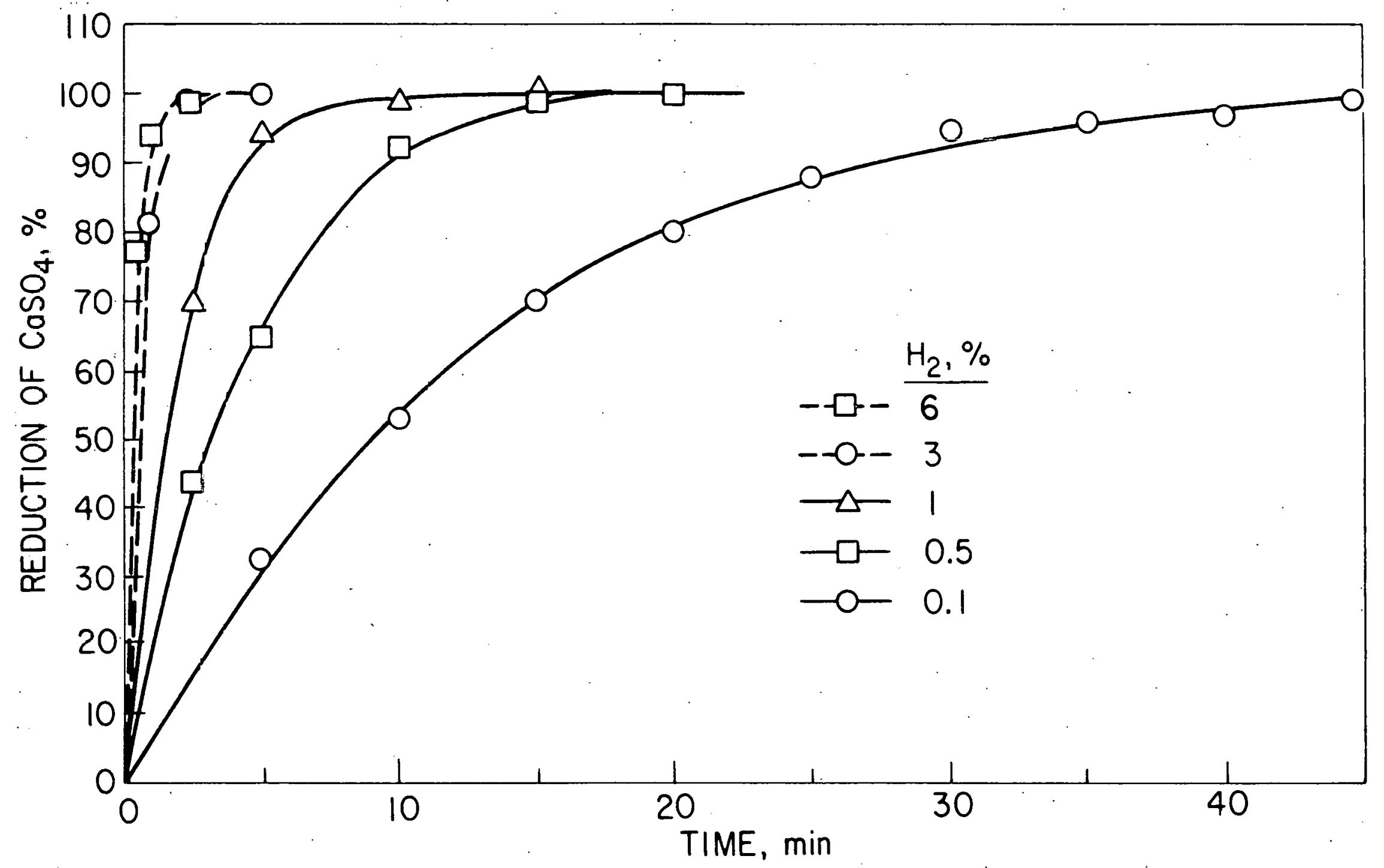

Fig. 10. Rate of Regeneration of $\mathrm{CaSO}_{4}$ in $\alpha-\mathrm{Al}_{2} \mathrm{O}_{3}$ using Indicated Concentrations of Hydrogen (the balance nitrogen) at $1100^{\circ} \mathrm{C}$. 


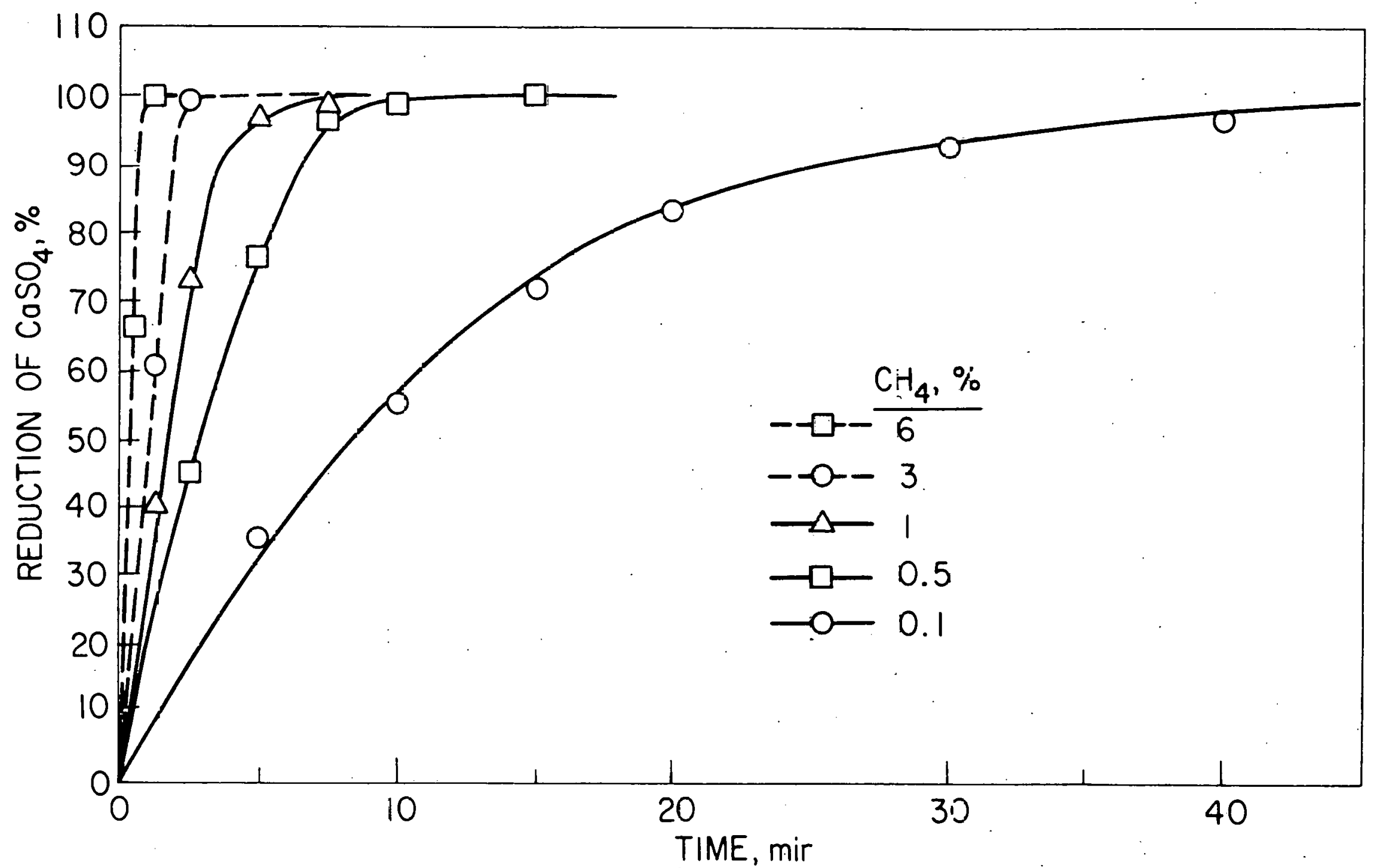

Fig. 11. Rate of Regeneration of $\mathrm{CaSO}_{4}$ in $\alpha-\mathrm{Al}_{2} \mathrm{O}_{3}$ using Inilicated Concentrations of Methane (the belance--nitrogen) $a=1100^{\circ} \mathrm{C}$. 
Table 5. Calculated Regeneration of $\mathrm{CaSO}_{4}$ to $\mathrm{CaO}$

\begin{tabular}{|c|c|c|c|}
\hline \multirow[b]{2}{*}{$\begin{array}{l}\text { Reducing } \\
\text { Gas Conc, \% }\end{array}$} & \multicolumn{3}{|c|}{ Calculated Completeness of Regeneration, } \\
\hline & Co & $\mathrm{H}_{2}$ & $\mathrm{CH}_{4}$ \\
\hline 6 & 102 & 93 & 87 \\
\hline 3 & 102 & 99 & 109 \\
\hline 1 & 96 & 106 & 98 \\
\hline 0.5 & 86 & 108 & 89 \\
\hline 0.1 & 110 & 103 & 92 \\
\hline
\end{tabular}

Effect of $\mathrm{CO}_{2}$ in Reducing Gas on Regeneration Rate

The effect of $\mathrm{CO}_{2}$ concentration in the reducing gas on the regeneration rate of sulfated sorbent supported on $\alpha-\mathrm{Al}_{2} \mathrm{O}_{3}$ is being studied. Carbon dioxide should decrease the rate due to the thermodynamically favorable reaction of $\mathrm{CO}_{2}$ with $\mathrm{H}_{2}$ to form $\mathrm{H}_{2} \mathrm{O}$ and $\mathrm{CO}$.

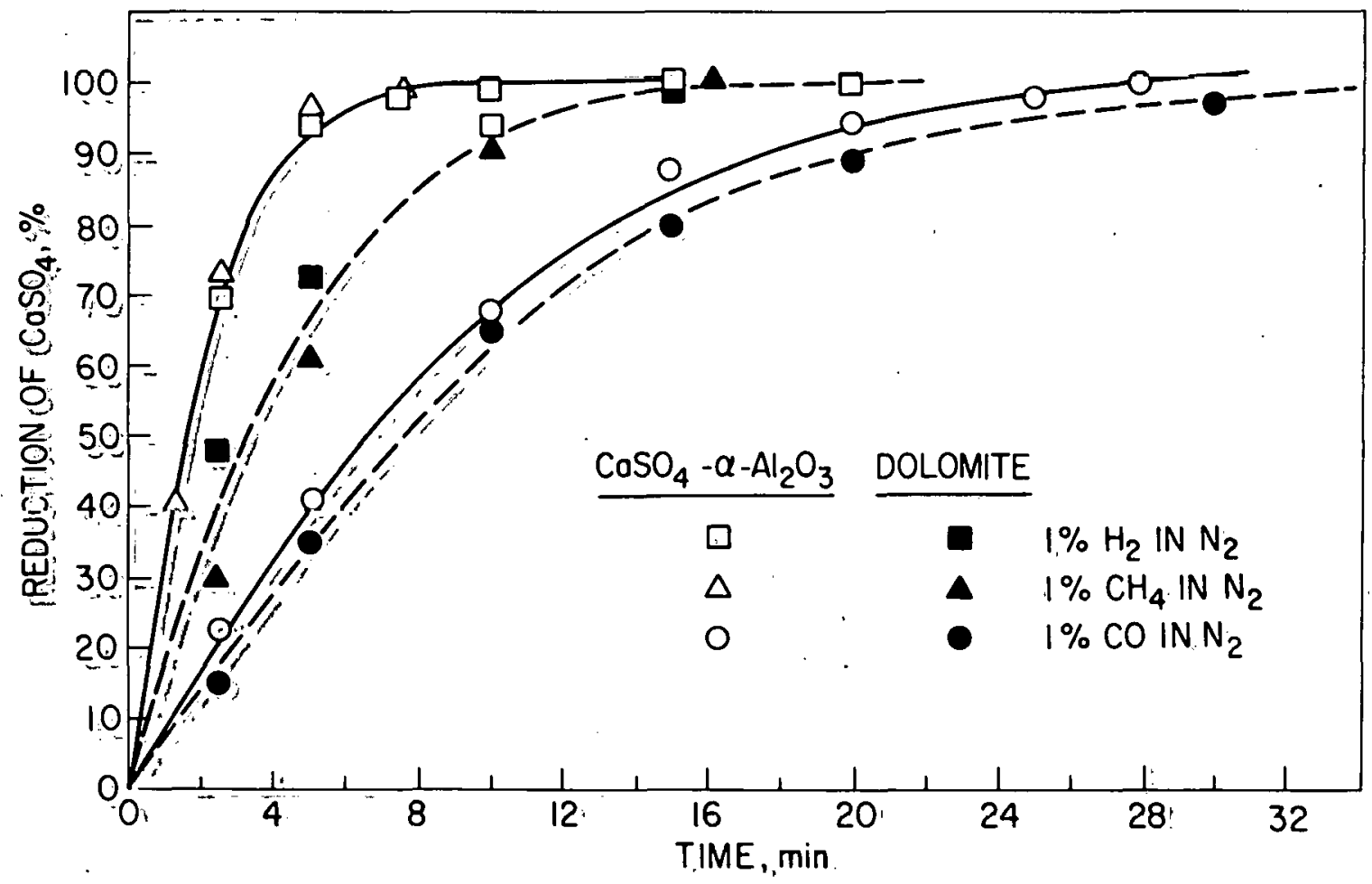

Fig.; 12. Comparison of the Rates of Regeneration of $\mathrm{CaSO}_{4}-\alpha-\mathrm{Al}_{2} \mathrm{O}_{3}$ and Sulfated Dolomite, using $1 \%$ Methane, Hydrogen,. or Carbon. Monoxide at $1100^{\circ} \mathrm{C}$ 
Table 6. Carbon Content of Pellets after Regeneration with Methane

\begin{tabular}{crc}
\hline $\begin{array}{c}\text { Reducing Gas and its } \\
\text { Concentration in } \\
\text { Experiment }\end{array}$ & \multicolumn{2}{c}{ Pellets } \\
\cline { 2 - 3 } & Carbon, ppm & Carbon, $^{\mathrm{a}} \mathrm{mg} / 35 \mathrm{mg}$ pellets \\
\hline $6 \% \mathrm{CH}_{4}$ & 8500 & 0.41 \\
$1 \% \mathrm{CH}_{4}$ & 400 & 0.15 \\
$0.5 \% \mathrm{CH}_{4}$ & 200 & 0.07 \\
$3 \% \mathrm{H}_{2}$ & & 0.04 \\
\hline
\end{tabular}

$\mathrm{a}_{1.3 \mathrm{mg}}$ of $\mathrm{C}$ from the reduction of $\mathrm{CH}_{4}$ to $\mathrm{H}_{2}+\mathrm{C}$ would be needed in a 35-mg pellet to obtain enough $\mathrm{H}_{2}$ to reduce all $\mathrm{CaSO}_{4}$ in the pellet to $\mathrm{CaO}$.

$\Lambda_{A} \mathrm{~S}$ reported above, when $\mathrm{CO}$ was used as the reducing gas, the rate of regeneration was approximately one-third that when hydrogen was used. In runs to examine the effect of $\mathrm{CO}_{2}$ concentration, the rate seemed to decrease only when the $\mathrm{CO}_{2}$ concentration became larger than $15 \%$ (Fig. 13).

Comparison of Regeneration Rates of Sulfated Pellets and Sulfated Tymochtee Dolomite

In an attempt to generate meaningful data applicable to pilot plant fluidized-bed regeneration experiments, Tymochtee dolomite that had been sulfated in the coal-fired, fluidized-bed combustor was reduced using $\mathrm{CO}, \mathrm{H}_{7}$, and $\mathrm{CH}_{4}$ at $3 \%$ and $1 \%$ concentrations for somparisnn with regenera= tion of the supported additive pellets. Data are plotter in Fig. 14 for $3 \%$ reducing gas concentration. The dnlnmite rnntained $10.1 \% \mathrm{~S}$ and was expected to lose about three times more sulfur than the pellets during regcnerations. Also the pellets were approximately three times larger than the dolomite particles.

The regeneration rates for do1nmite were somewhat lower than thooc for the additive pellets; the decomposition rate of $\mathrm{CaSO}_{4}$ in the dolomite decreased rapidly near the end of the reaction. This decrease in rate was not observed for the pellets. However, the residence times in a regenerator would not differ significantly for dolomite or pellets.

The major difference was the product found at the end of the reaction. As stated above, for the pellets, the products were $\mathrm{CaO} \cdot \mathrm{AI}_{2} \mathrm{O}_{3}$ and $\mathrm{CaO} \cdot 2 \mathrm{Al}_{2} \mathrm{O}_{3}$; for dolomite, the products were $\mathrm{CaO}$ and $\mathrm{CaS}$. (In neither case was $\mathrm{CaSO}_{4}$ found.) Wet chemical analysis will be used to quantify the amount of $\mathrm{CaS}$ in the dolnmite. X-ray diffraction data indicate that CaS might constitute as much as $30-50 \%$ of the product. 


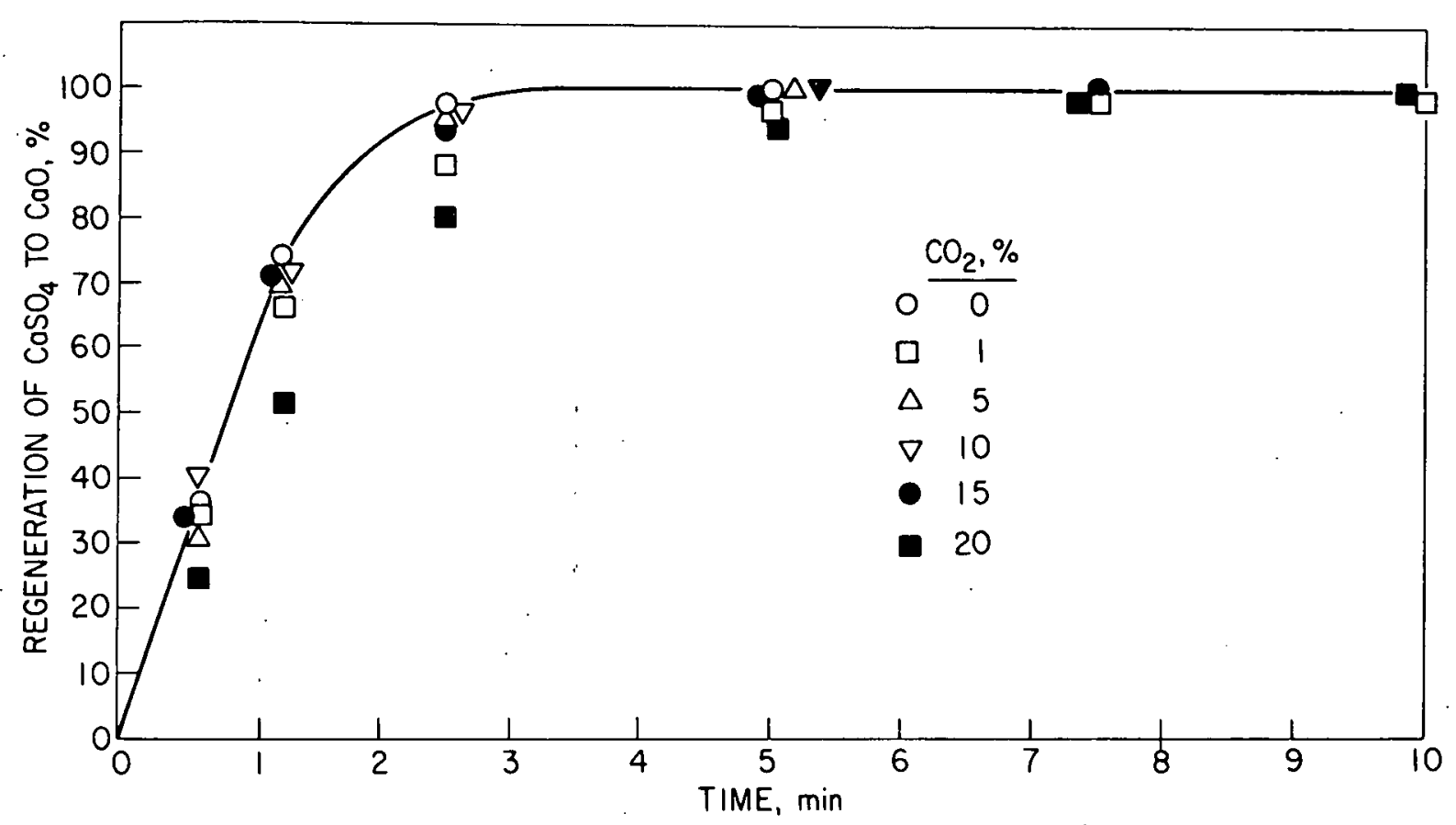

Fig. 13. Effect of $\mathrm{CO}_{2}$ Concentration in the Reducing Gas on the Rate of Regeneration of Sulfated $6.6 \% \mathrm{CaO}$ in $\alpha-\mathrm{Al}_{2} \mathrm{O}_{3}$ at $1100^{\circ} \mathrm{C}$. Regeneration Cas: $1 \% \mathrm{CO}, 1 \% \mathrm{H}_{2}, 1 \% \mathrm{CH}_{4}$ in $\mathrm{N}_{2}+$ indicated $\mathrm{CO}_{2}$

The SEM results showed that most of the sulfur in the dolomite was near the surface of the particles. This is not surprising since these particles were only $50 \%$ sulfated in the combustor before being reduced in the TGA. It should also be noted that both iron and chlorine were also found on the dolomite surface.

\section{Cyclic Sulfation-Regeneration Studies}

Ten cyclic sulfation-regeneration reactions were performed to determine if any loss in reactivity would occur as a function of the number of cycles. After each sulfation and regeneration step, one pellet was removed for analysis. The percent calcium utilization in sulfation and the percent conversion of $\mathrm{CaSO}_{4}$ to $\mathrm{CaO}$ during regeneration of the sulfated pellets were calculated from the analyses and are given in Table 7 . Over $93 \%$ calcium utilization was found in all cycles except the initial sulfation cycle.

In Figs. 15 and 16, the rates of sulfation for cycles 1 to 10 are given. The sulfation rate for cycle 2 was much lower than for cycle 1 . In following cycles, the rate increased with each cycle up to cycle 7, where the rates became essentially constant. The pellets had been heattreated at $800^{\circ} \mathrm{C}$ during preparation. However, during regeneration at 


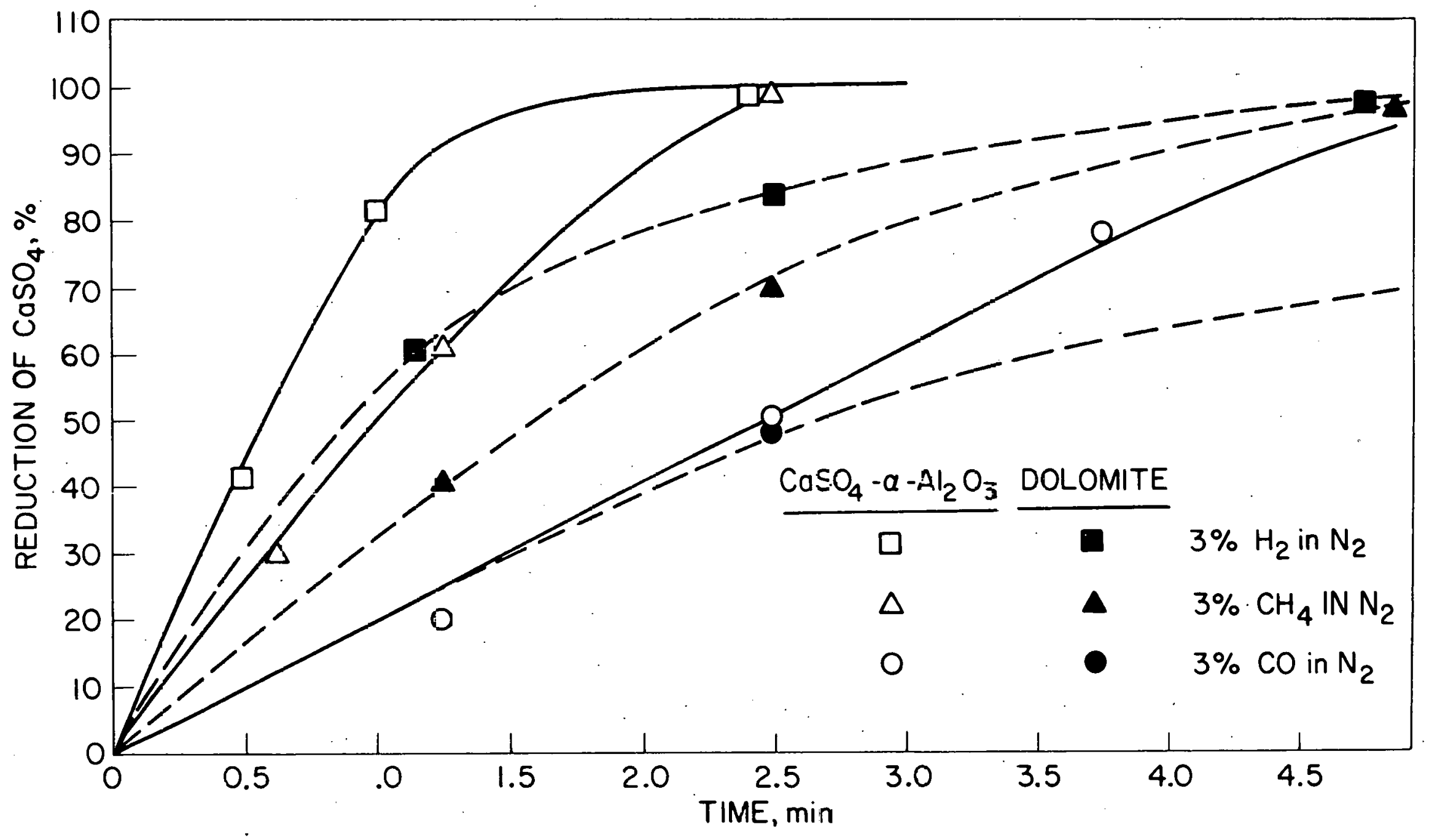

Fig. 14. Comparison of the Rate of Regenerazion of $\mathrm{CaSC}_{4}-\mathrm{a}_{-}-\mathrm{Al}_{2} \mathrm{O}_{3}$ and Sulfated Dolomite using $3 \% \mathrm{CH}_{4}, \mathrm{H}_{2}$, or $\mathrm{CO}$ at $1100^{\circ} \mathrm{C}$ 
Table 7. Completeness of Sulfation and Regeneration in Cyclic Experiment

\begin{tabular}{rrrr}
\hline \multicolumn{2}{c}{ Sulfation } & \multicolumn{2}{c}{ Regeneration } \\
\cline { 3 - 4 } Cycle & $\begin{array}{c}\text { Completeness of } \\
\text { Sulfation, } \%\end{array}$ & Cycle & $\begin{array}{c}\text { Completeness of } \\
\text { Regeneration, } \%\end{array}$ \\
\hline 1 & 85.3 & 1 & 95.2 \\
2 & 98.8 & 2 & 96.4 \\
3 & 97.0 & 3 & 97.4 \\
4 & 96.1 & 4 & 97.6 \\
5 & 95.3 & 5 & 96.9 \\
6 & 93.3 & 6 & 94.3 \\
7 & 93.5 & 7 & 95.0 \\
8 & 94.4 & 8 & 97.1 \\
9 & 97.3 & 9 & 95.4 \\
10 & 93.2 & 10 & 96.3 \\
\hline
\end{tabular}

${ }^{\mathrm{a}} \mathrm{Calculations}$ based on the assumption that the pellets originally contained $6.6 \% \mathrm{CaO}$ in $\alpha$-alumina. The data in Figs. 15 and 16, in contrast, are based on the assumption that $100 \%$ of the material reacted.

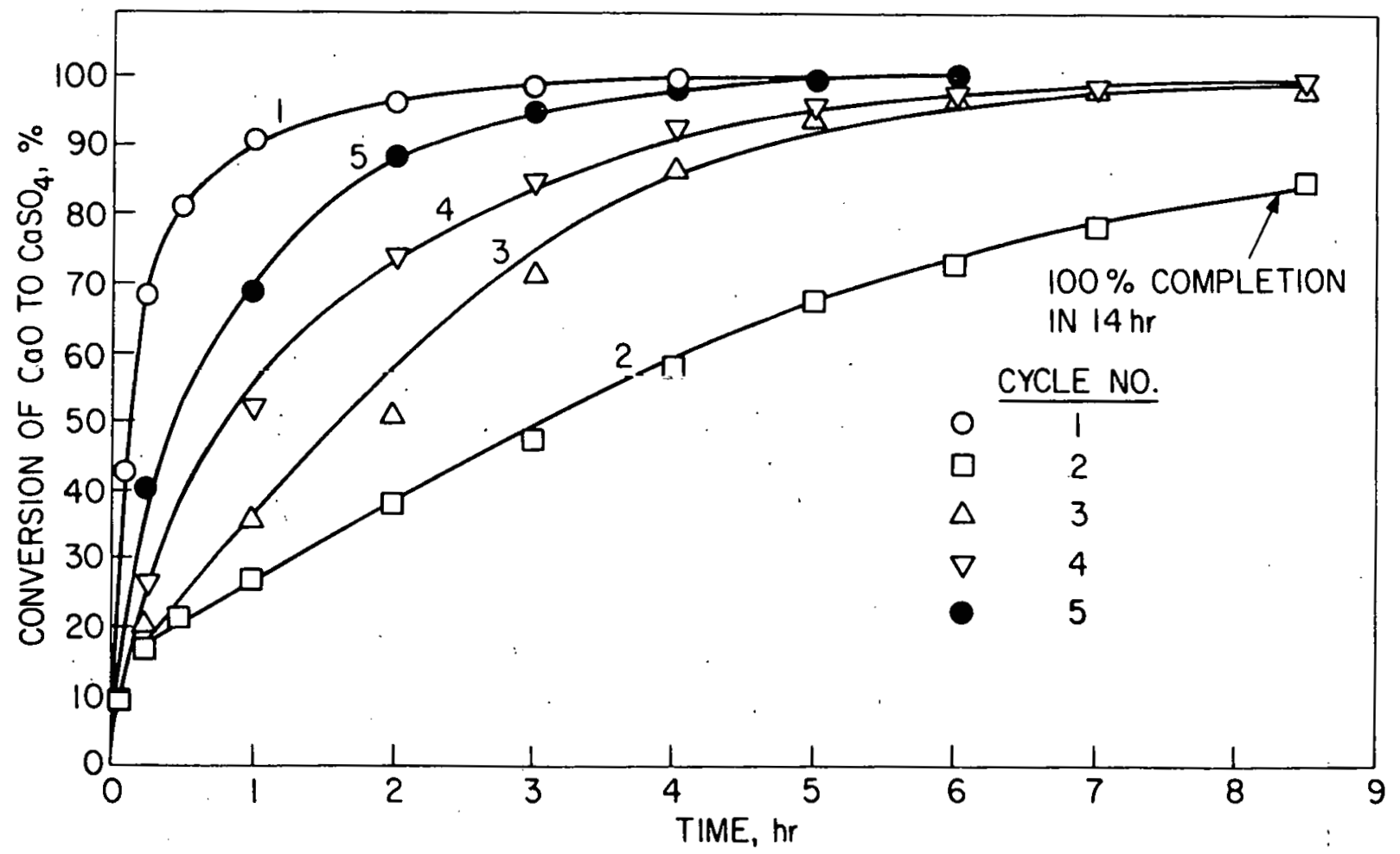

Fig. 15. Comparison of Sulfation Rates in Various Cycles at $900^{\circ} \mathrm{C}$, Using $6.6 \% \mathrm{CaO}$ in $\alpha-\mathrm{Al}_{2} \mathrm{U}_{3}$. Sulfation Gas Mixture: $3 \% \mathrm{30}_{2}$, $5 \% \mathrm{O}_{2}$, in $\mathrm{N}_{2}$. 


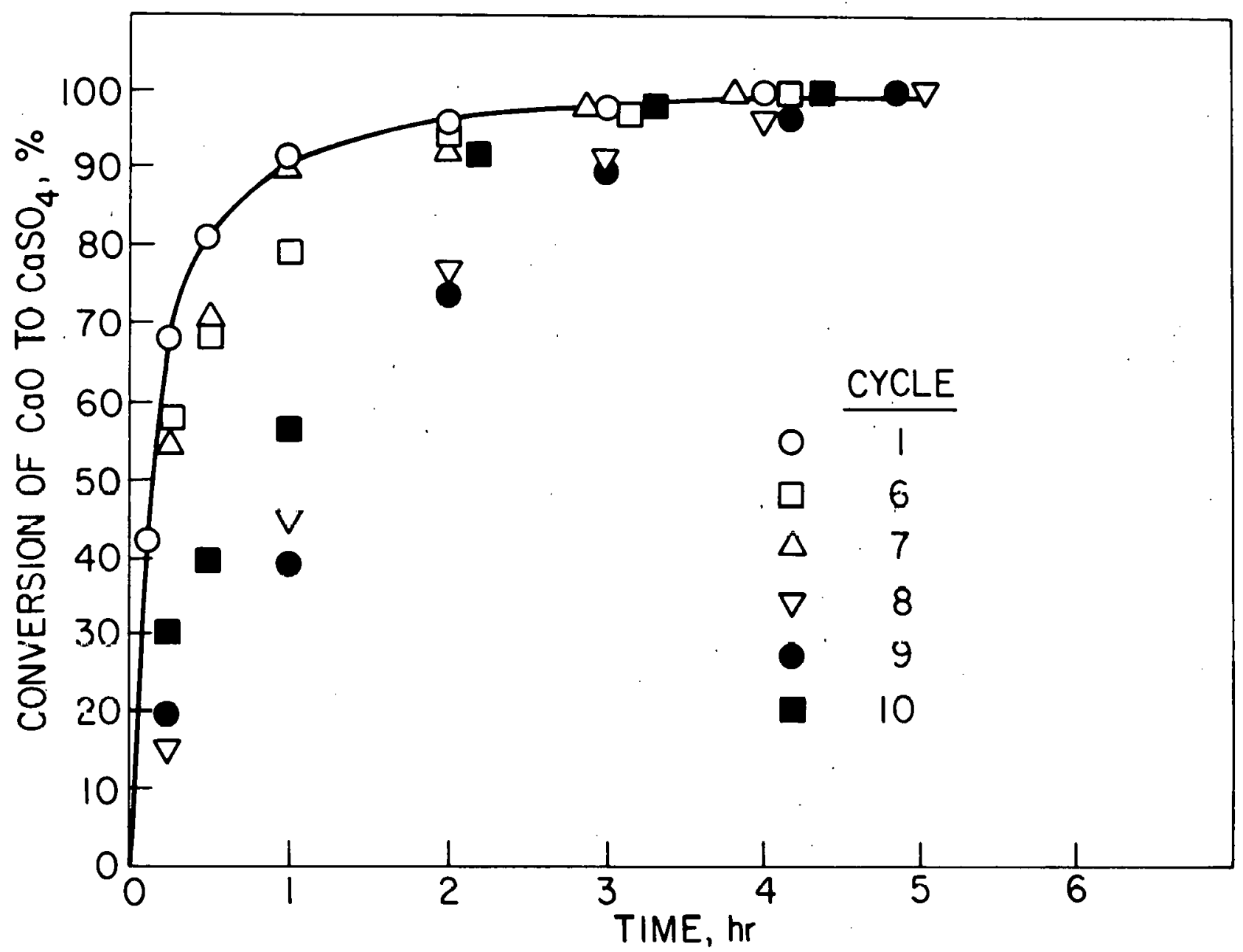

Fig. 16. Comparison of Sulfation Rate in Various Cycles for 6.6\% $\mathrm{CaO}$ in $\alpha-\Lambda 1 \% 0_{3}$ at $900^{\circ} \mathrm{C}$. Sulfation Gas Mixture: $3 \% \mathrm{SO}_{2}$ and $5 \% \mathrm{O}_{2}$ in $\mathrm{N}_{2}$

$1100^{\circ} \mathrm{C}$, different calcium aluminates were formed; it is thought that this caused the different rates of sulfation. In the future, cyclic tests will be performed on pellets that have first been heat treated at $1100^{\circ} \mathrm{C}$.

In Fig. 17, the rates of regeneration are given for cycles 1 to 10 (no data were obtained for cycle 9 ). Pellets in cycles 1 to 7 were reduced using $3 \% \mathrm{H}_{2}$; in cycles 8,9 , and 10 they were reduced using $1 \%$ $\mathrm{H}_{2}$. The rates of regeneration were similar for cycles in which the same concentration of hydrogen was used. 


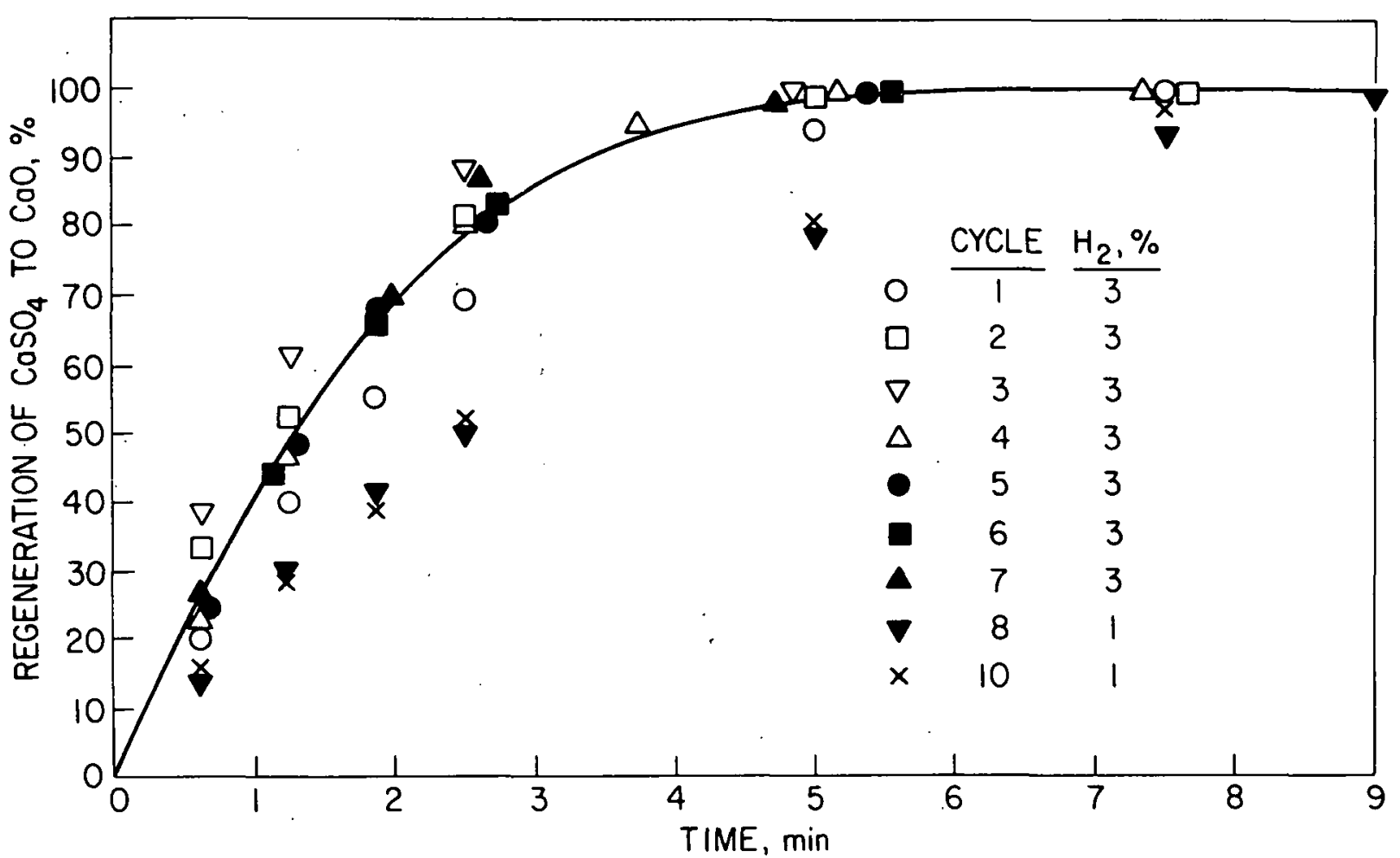

Fig. 17. Comparison of Regeneration Rates in Various Cycles for $6.6 \%$ $\mathrm{CaO}-\alpha-\mathrm{Al}_{2} \mathrm{O}_{3}$ at $1100^{\circ} \mathrm{C}$. Regeneration Gas Mixture: $\mathrm{H}_{2}$ in $\mathrm{N}_{2}$

\section{SULFUR EMISSION CONTROL CHEMISTRY}

Additional results are presented on the solid-solid reaction

$$
3\left[\mathrm{CaSO}_{4} \cdot \mathrm{MgO}\right]+[\mathrm{CaS} \cdot \mathrm{MgO}] \rightarrow 4[\mathrm{CaO} \cdot \mathrm{MgO}]+4 \mathrm{SO}_{2}
$$

Initial results on the feasibility of this regeneration method were given in a previous report. ${ }^{4}$ The emphasis in the efforts being reported herein has been twofold: (a) to investigate the nature of the effects caused by varying the composition of the starting material for the solid-solid reaction, and (b) to initiate a study of the correlation between TGA results and the results obtained from application of the earlier reported $\mathrm{X}$-ray method. ${ }^{4}$

The experimental procedure employed was as follows: A large stock supply of sulfated dolomite No. 1337 was prepared, and stones from this stock supply were used in every experiment. The sulfated dolomite stock supply was prepared by half-calcining the stone and subsequently sulfating in a $4 \% \mathrm{SO}_{2}, 5 \% \mathrm{O}_{2}$ simulated flue gas mixture until the gaining of weight halted. 
The starting materials for experiments to study the solid-solid reaction, Eq. (1), were always prepared under identical conditions, i.e., aliquots of sulfated dolomite were reduced to the desired extent, using a gas mixture containing $3 \% \mathrm{H}_{2}$ and the balance helium at a reaction temperature of $880^{\circ} \mathrm{C}$. Starting materials were prepared that had sulfide concentrations of 24 .to $39 \%$ (by TGA analysis).

In addition, all sulfate-sulfide reaction experiments were performed under the same conditions, $i . e$. , under 1 -atm partial pressure of helium at $950^{\circ} \mathrm{C}$. Most sulfate-sulfide reaction experiments were run for $5 \mathrm{hr}$, but some were run overnight.

$X$-ray diffraction analyses were performed on samples of the starting material and on samples of the products of all sulfate-sulfide reaction experiments. In all cases, aliquots of 30 to 50 stones were analyzed to minimize sampling error problems.

The results of these experiments are summarized in Table 8 . The first column identifies the experiment and the sample analyzed by X-ray, and the second column gives the sample history. The third through the seventh columns list TGA results. The third column gives the percentage of the available material in the stones that has been converted. The fourth, fifth, and sixth columns give the compositions of the samples as percentages of maximum weights possible of $\mathrm{CaO}, \mathrm{CaSO}_{4}$, and $\mathrm{CaS}$, respectively. ("Maximum weights possible" refers to a pure species, e.g., for the fourth column, $100 \% \mathrm{CaO}$, with no $\mathrm{CaSO}_{4}$ or $\mathrm{CaS}$ ). The seventh column lists calcium material balances as total percentage of calcium species existing in the stones. The eighth through the eleventh columns 1ist $\mathrm{X}$-ray diffraction results. Columns eight, nine, and ten give the compositions of the samples as percentages of the maximum weights possible of $\mathrm{CaO}, \mathrm{CaSO}_{4}$, and $\mathrm{CaS}$, respectively. The eleventh column lists the X-ray calcium species material balances as total percentages calcium existing in the stones.

Varying the composition of the starting material for the solid-solid reaction had the following effects: In all cases, the increase in $\mathrm{CaO}$ concentration was substantial, that is, in the 30 to $60 \%$ range. However, it is apparent from columns 3 and 8 that a starting material containing greater than $25 \%$ sulfide (the stoichiometry of $\mathrm{Eq}$ : (1) indicates that $25 \%$ sulfide is required) is necessary to approach higher yields (i.e., consumption of most of the $\mathrm{CaSO}_{4}$ and $\mathrm{CaS}$ before the reaction stops). For example, in experiment II, in which the starting material contained $25 \%$ of the CaS form, the CaS was completely consumed and a substantial amount of $\mathrm{CaSO}_{4}$ remained when reaction ceased. From these preliminary result.s, it is believed necessary that a starting material contain about $35 \%$ of the reduced form to force the solid-solid reaction toward completion at a reaction temperature of $950^{\circ} \mathrm{C}$. Continued investigation is planned to determine if the reaction will go to completion and to gain an understanding of why overreduction is necessary. 
Zable 8. Summary of TGA and X-Ray Results for Solid-Solid Reaction Experiments at $950^{\circ} \mathrm{C}$

\begin{tabular}{|c|c|c|c|c|c|c|c|c|c|c|}
\hline \multirow[b]{2}{*}{$\begin{array}{c}\text { Experiment } \\
\text { Number - } \\
\text { Sample } \\
\text { Number } \\
\end{array}$} & \multirow[b]{2}{*}{$\begin{array}{l}\text { Sample } \\
\text { Histo:y }\end{array}$} & \multicolumn{5}{|c|}{ TGA Results } & \multicolumn{4}{|c|}{ X-ray Diffraction Results } \\
\hline & & $\begin{array}{c}\text { Available } \\
\text { material } \\
\text { converted, } \\
\%\end{array}$ & $\begin{array}{l}\text { Fercent. of } \\
\text { maximum } \\
\text { weight of } \\
\text { CaO possible }\end{array}$ & $\begin{array}{l}\text { Percent of } \\
\text { maximum } \\
\text { weight of } \\
\mathrm{CaSO}_{4} \text { possible }\end{array}$ & $\begin{array}{l}\text { Percent of } \\
\text { maximum } \\
\text { weight of } \\
\text { CaS possible }\end{array}$ & $\begin{array}{c}\text { Total } \\
\mathrm{Ca} \\
\%\end{array}$ & $\begin{array}{l}\text { Percent of } \\
\text { maximum } \\
\text { weight of } \\
\mathrm{CaO} \text { possible }\end{array}$ & $\begin{array}{l}\text { Percent of } \\
\text { maximum } \\
\text { weight of } \\
\mathrm{CaSO}_{4} \text { possible }\end{array}$ & $\begin{array}{l}\text { Percent of } \\
\text { maximum } \\
\text { weight of } \\
\text { CaS possible }\end{array}$ & $\begin{array}{c}\text { Total } \\
\text { Ca } \\
\%\end{array}$ \\
\hline I & $\begin{array}{l}\text { Stock } \\
\text { Material }\end{array}$ & $\begin{array}{c}92 \% \\
\text { sulfated }\end{array}$ & 15 & 85 & 0 & 100 & 11 & 64 & 4 & 79 \\
\hline II-A & $\begin{array}{l}\text { Partial } \\
\text { Reducion }\end{array}$ & $\begin{array}{c}25 \% \\
\text { reduced }\end{array}$ & 15 & 64 & 21 & 100 & 13 & 62 & $--^{b}$ & 75 \\
\hline$E I-B$ & $\begin{array}{l}\text { Sulfa:e-sulfide } \\
\text { reaction, } 5 \mathrm{hr}\end{array}$ & $--^{a}$ & $--^{a}$ & $--^{a}$ & $--^{a}$ & $--^{a}$ & 40 & 42 & $--^{b}$ & 83 \\
\hline I I-C & $\begin{array}{l}\text { Sulfaze-sulfide } \\
\text { reaction, over- } \\
\text { night }\end{array}$ & $--^{a}$ & $--^{a}$ & $--^{a}$ & $--^{a}$ & $--^{a}$ & 58 & 21 & $--^{b}$ & 79 \\
\hline III $-A$ & $\begin{array}{l}\text { Partial } \\
\text { Reduction }\end{array}$ & $\begin{array}{c}32 \% \\
\text { reduced }\end{array}$ & 15 & 58 & 27 & 100 & 12 & 66 & 10 & 88 \\
\hline III-B & $\begin{array}{l}\text { Sulfate-sulfide } \\
\text { reaction, } 5 \mathrm{hr}\end{array}$ & e $\quad--a$ & $-_{-{ }^{a}}^{a}$ & $--^{a}$ & $-a^{a}$ & $--^{a}$ & 58 & 12 & 7 & 77 \\
\hline IV-A & $\begin{array}{l}\text { Partial } \\
\text { Reduction }\end{array}$ & $\begin{array}{c}36 \% \\
\text { reduced }\end{array}$ & 15 & 54 & 31 & 100 & 15 & 58 & 20 & 93 \\
\hline$I V-B$ & $\begin{array}{l}\text { Sulfate-sulfide } \\
\text { reaction, } 5 \mathrm{hr}\end{array}$ & e $\quad--^{a}$ & $--^{a}$ & $--^{a}$ & $-^{a}$ & $--^{a}$ & 43 & 19 & ${ }^{-b}$ & 62 \\
\hline $\mathrm{V}-\mathrm{A}$ & $\begin{array}{l}\text { Partial } \\
\text { Reduction }\end{array}$ & $\begin{array}{c}36 \% \\
\text { reduced }\end{array}$ & 15 & 54 & 31 & 100 & 15 & 58 & 16 & 89 \\
\hline $\mathrm{V}-\mathrm{B}$ & $\begin{array}{l}\text { Sulfate-sulfide } \\
\text { reaction, over- } \\
\text { night }\end{array}$ & $e^{-} \quad--^{a}$ & $--^{a}$ & $--^{a}$ & $--^{a}$ & $--^{a}$ & 68 & 7 & 4 & 79 \\
\hline VI-A & $\begin{array}{l}\text { Partial } \\
\text { Reduction }\end{array}$ & $\begin{array}{c}40 \% \\
\text { reduced }\end{array}$ & 15 & 51 & 34 & 100 & 10 & 57 & 21 & 88 \\
\hline$V I-B^{-}$ & $\begin{array}{l}\text { Sulfate-sulfide } \\
\text { reaction, } 5 \mathrm{hr}\end{array}$ & e $\quad--^{a}$ & $-\dot{a}^{a}$ & $-^{a}$ & $--^{a}$ & $--^{a}$ & 49 & 14 & 13 & 76 \\
\hline
\end{tabular}

${ }^{a}$ Due to the manner in which these experiments were performed, it was not possible to monitor sulfate-sulfide reaction progress from TGA weight changes.

${ }^{b} \mathrm{CaS}$ lines in X-ray patterns were either not detectable or, when detectable, were not intense enough to measure. 
The following observations refer to correlations between TGA and X$X$-ray results. (Unfortunately, due to the manner in which these experiments were performed, quantitative comparison of TGA and X-ray results is possible only for reduction reaction. In the future, it is planned to design experiments to allow comparison of the two types of results. for the solid-solid reaction.)

Comparison of TGA and X-ray results for the reduced stones (Table 8, columns 4 and 8 and columns 5 and 9 ) in each of the experiments suggests that the two methods are generally in agreement. The agreement for the amounts of $\mathrm{CaO}$ and $\mathrm{CaSO}_{4}$ in the samples is extremely good. However, the agreement for the amount of CaS present is not as good as might be hoped; in each case, the X-ray result is lower than the TGA result. In addition, the $\mathrm{X}$-ray method yields a poor material balance, as indicated by the values in the eleventh column in Table 8 , which are always less than $100 \%$. Any of a number of factors might lead to experimenta1 errors that could cause the lack of agreement: (a) the use of peak heights instead of integrated intensities, (b) the presence of amorphous materials, and (c) complete masking of the usable CaS lines by the $\mathrm{CaSO}_{4}$ lines, leading to substantial error in the CaS estimates. The use of a diffractometer to obtain line intensity measurements should greatly reduce the errors calısed by factors (a) and (c).

The MgO has been used as a reference standard. However, it has been observed that a line shift is sometimes present at large scattering angles. This can occur when a solid solution of an unknown material exists in the MgO phase. The net result can be to modify the MgO line intensities to some extent. It has also been observed that the 004 and 040 line combination of $\mathrm{CaSO}_{4}$ is, for some reason, generally weaker than expected. All of these factors have an effect on accurary.

Two additional experiments were performed to study the feasibility of the reaction between calcium sulfate and calcium sulfide as a viable regeneration scheme. In these experiments, partially calcined sulfated dolomite particles (experiment CAS-10) and fully calcined sulfated dolomite particles (experiment CAS-12), both from the VAR-7

combustion experiment performed previously in the ANL 6-in.-dia, fluidized bed combustor, were reacted with a stoichiometric excess of CaS.

The experiments were performed by packing a mixture of $290 \mathrm{~g}$ of sulfated dolomite $\left(34.8 \% \mathrm{CaSO}_{4}\right)$ and $22.3 \mathrm{~g}$ of $\mathrm{CaS}$ into a quartz reactor tube and heating to $1025^{\circ} \mathrm{C}\left(1877^{\circ} \mathrm{F}\right)$. A stream nf nit.rngen gas provided a neutral atmosphere, as well as the purge medium. During the heatup periud ( $u 4 \mathrm{hr}$ ) and after temperature stabilization, the of $\overline{\mathrm{f}}$-gas was monitored continuously for $\mathrm{SO}_{2}$ content, using an infrared analyzer. offgas samples were also taken at various times for analysis with a mass spectrometer to check analyzer accuracy and to determine what other constituents were in the gas stream. X-ray diffraction analysis was used to determine the composition of the product solids. Table 9 lists the reactants, reaction times, major products, amounts of $\mathrm{SO}_{2}$ produced, and estimates of the completeness of reaction. 
Table 9. Reaction of Calcium Sulfate with Calcium Sulfide in Experiments CAS-10 and CAS-12

\begin{tabular}{|c|c|c|c|c|c|c|c|}
\hline \multirow[b]{2}{*}{$\begin{array}{l}\text { Exp. } \\
\text { No. }\end{array}$} & \multirow[b]{2}{*}{ Reactants } & \multirow[b]{2}{*}{$\begin{array}{l}\text { Reaction } \\
\text { Time }\end{array}$} & \multirow[b]{2}{*}{$\begin{array}{l}\text { Major } \\
\text { Products }\end{array}$} & \multirow[b]{2}{*}{$\begin{array}{c}\text { Max Conc } \\
\text { of } \mathrm{SO}_{2} \\
\text { in the } \\
\text { off-gas, } \\
\%\end{array}$} & \multicolumn{3}{|c|}{$\begin{array}{c}\text { Reaction Completeness, \%, } \\
\text { Based on }\end{array}$} \\
\hline & & & & & $\begin{array}{l}\text { Wt Loss } \\
\text { due to } \\
\mathrm{SO}_{2} \text { Prod. }\end{array}$ & $\begin{array}{l}\text { Total } \\
\mathrm{SO}_{2} \text { (Gas } \\
\text { analysis) }\end{array}$ & $\begin{array}{l}\mathrm{CaO} \\
\text { Prod. } \\
\text { (Solid } \\
\text { analysis) }\end{array}$ \\
\hline CAS-10 & $\begin{array}{l}\text { partially } \\
\text { calcined } \\
\text { sulfated } \\
\text { dolomite } \\
\text { (93.8 g); } \\
\text { CaS }(23.2 \mathrm{~g}\end{array}$ & $\sim 7 \mathrm{hr}^{\mathrm{a}}$ & $\mathrm{CO}_{2}, \mathrm{SO}_{2}$ & 1.1 & $<2$ & $<5$ & $<5$ \\
\hline CAS-12 & $\begin{array}{l}\text { fully } \\
\text { calcined } \\
\text { sulfated } \\
\text { dolomite } \\
(89.2 \mathrm{~g}) ; \\
\text { Cas }(23.2 \mathrm{~g})\end{array}$ & $243 \mathrm{hr}^{\mathrm{c}}$ & $\mathrm{SO}_{2}, \mathrm{CaO}$ & 10.5 & 90 & น88 & $\sim 50^{d}$ \\
\hline
\end{tabular}

a Terminated after this time because $\mathrm{SO}_{2}$ concentration romaincd at $0.1 \%$ for $25 \mathrm{hr}$ after the peak level of $1.1 \%$ was reached.

$\mathrm{b}_{\text {Heated in }}$ air to $850^{\circ} \mathrm{C}\left(1550^{\circ} \mathrm{F}\right)$ for approx. $16 \mathrm{hr}$.

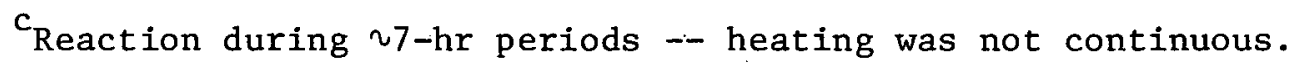

d Subject to change after X-ray diffraction patterns obtained by the use of more appropriate standards are completed.

Experiment CAS-10 was designed to determine if calcium sulfide would react with partially calcined, sulfated dolomite to produce a high concentration of $\mathrm{SO}_{2}$ in the off-gas stream. Little reaction occurred. A possible explanation is that the $\mathrm{CaS}$ is oxidized by $\mathrm{CO}_{2}$ (released from the calcining dolomite), forming more $\mathrm{CaSO}_{4}$ and thus inhibiting the solid-solid reaction. ${ }^{6}$

The reaction of CaS with fully calcined sulfated dolomite (experiment CAS-12) had more favorable results. Figure 18 illustrates the concentration of $\mathrm{SO}_{2}$ produced as a function of time and temperature during CAS-12. As indicated in Fig. 18, the concentration of $\mathrm{SO}_{2}$ in the reactor off-gas varied from a high of $10.5 \%$ at $12 \mathrm{cc} / \mathrm{min}$ nitrogen flow to a low of $3.3 \%$ at $1000 \mathrm{cc} / \mathrm{min}$ nitrogen flow, the highest flow rate tested. Extrapolation of these data indicates that the $\mathrm{SO}_{2}$ equilibrium concentration with nitrogen present but no flow (at 1 atm) would be $\sim 11 \%$. This is near the theoretical value of $9 \%$ at $1877^{\circ} \mathrm{F}$ $\left(1025^{\circ} \mathrm{C}\right)$ as determined from the Zawadzki data plotted in Fig. 19. 
Figure 18 also shows that the maximum observed rate of reaction (33 $\mathrm{cc} \mathrm{SO}_{2} / \mathrm{min}$ ) occurred at the maximum nitrogen purge flow rate used during the experiment, $1000 \mathrm{cc} / \mathrm{min}$. This high a reaction rate may not be an advantage, however, in a conventional process (such as the Claus process) to convert the $\mathrm{SO}_{2}$ to elemental sulfur because such a process requires a high concentration of $\mathrm{SO}_{2}$ (such as those observed in this work at the lowest nitrogen flow rates) for economically attractive. operation.

$\mathrm{X}$-ray analyses of the CAS-12 product were also done to help determine where $\mathrm{CaO}$ formed in the additive particles. The diffraction. patterns indicated that most of the $\mathrm{CaO}$ produced was associated with the large dolomite stones, rather than being deposited as a residue with the powdered CaS reactant. Analysis of the fines indicated that only a minor portion was $\mathrm{CaO}$, and a very smail portion was $\mathrm{CaSO}_{4}$. Wet chemical analyses are planned to determine more precisely the reaction material balance.

Speculation regarding the mechanism that controls reaction (2), below, centered around a solid-gas-solid theory presented by Curran et $a l .8$ They postulated that this reaction

$$
3 / 4 \mathrm{CaSO}_{4}+1 / 4 \mathrm{CaS} \rightarrow \mathrm{CaO}+\mathrm{SO}_{2}
$$

represents the sum of three reactions:

$$
\begin{aligned}
& \mathrm{CaSO}_{4} \rightarrow \mathrm{CaO}+\mathrm{SO}_{3} \\
& \left.\quad \text { (Decomposition of } \mathrm{CaSO}_{4}\right) \\
& \mathrm{Su}_{3} \rightarrow \mathrm{SU}_{2}+\mathrm{I} / 2 \mathrm{U}_{2}
\end{aligned}
$$

(Decomposition of unstable $\mathrm{SO}_{3}$ )

and

$1 / 4 \mathrm{CdS}+1 / 2 \mathrm{O}_{2}=1 / 4 \mathrm{CaSO}_{4}$

(Combination of available $\mathrm{O}_{2}$ with unconverted CaS).

If this is the mechanism, the presence of CaS in at least a stoichiometric ratio to the $\mathrm{CaSO}_{4}$ serves as a facile route for the removal of oxygen from the system, which tends to promote reaction. It has been found in preliminary studies that to force the solid-solid reaction toward completion at $950^{\circ} \mathrm{C}$, a starting material containing about $35 \% \mathrm{CaS}$ may be necessary . The data obtained from the two experiments reported here are not in disagreement with this postulation. 


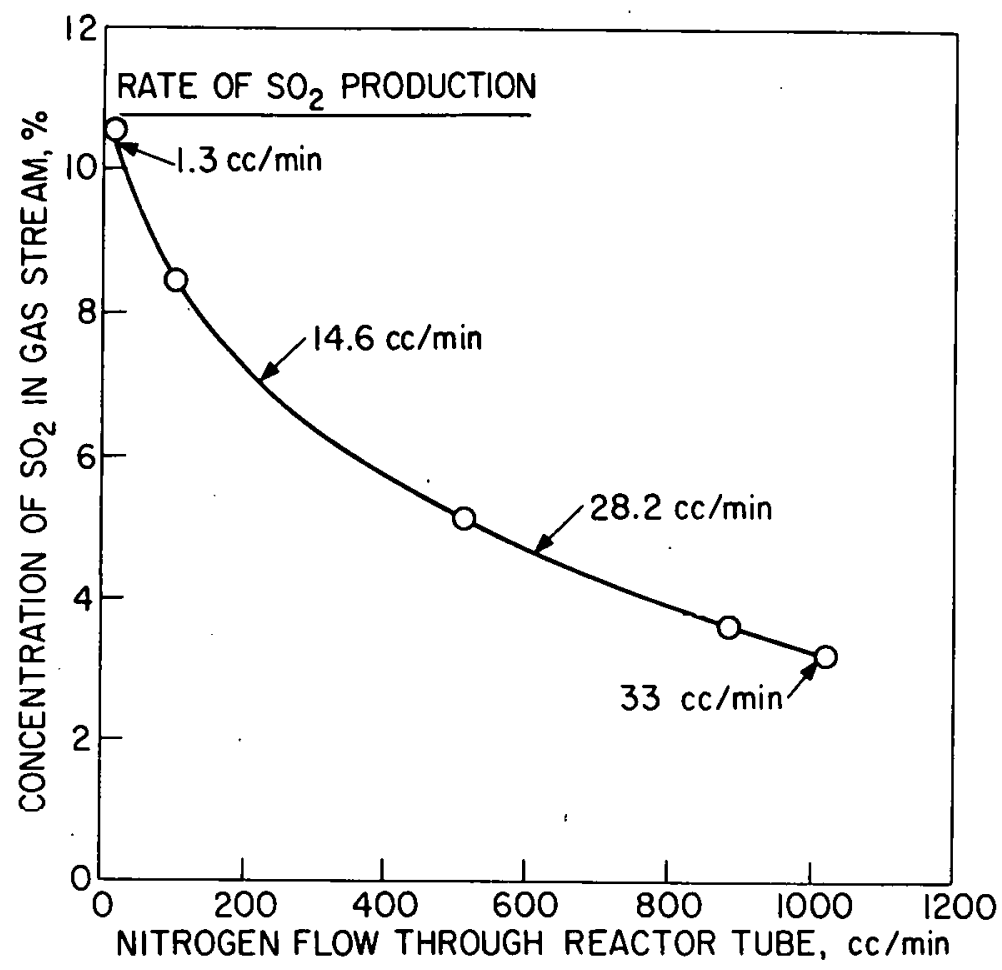

Fig. 18. Relationship of $\mathrm{SO}_{2}$ Production and Purge Flow Rate in SolidSolid Reaction. Temperature: $1025^{\circ} \mathrm{C}$; Purge gas: nitrogen; Reactants: $4: 3$ mole ratio, $\mathrm{CaS}: \mathrm{CaSO}_{4}\left(\mathrm{CaSO}_{4}\right.$ present as sulfated dolomite)

Plans have been made for additional investigation of the mechanism and feasibility of this approach as a regeneration scheme. An engineeringscale regeneration process would require that $\mathrm{CaS}$ be formed in situ (by the reduction of sulfated additive) rather than CaS being added. As a result, future laboratory experiments will be designed to reduce an appropriate fraction of the $\mathrm{CaSO}_{4}$ in the sulfated additive to CaS prior to solid-solid reaction. Also, since limited data have been gathered to date on temperature effects above $1025^{\circ} \mathrm{C}$, runs will be made at higher temperatures to obtain more temperature-reaction rate information.

COAL COMBUSTION REACTIONS

The Determination of Inorganic Constituents in the Effluent Gas from Coal Combustinn

Some chemical elements carried by combustion gas are known to cause severe metal corrosion. The objective of this study is to determine quantitatively which elements are present in the hot combustion gas of 


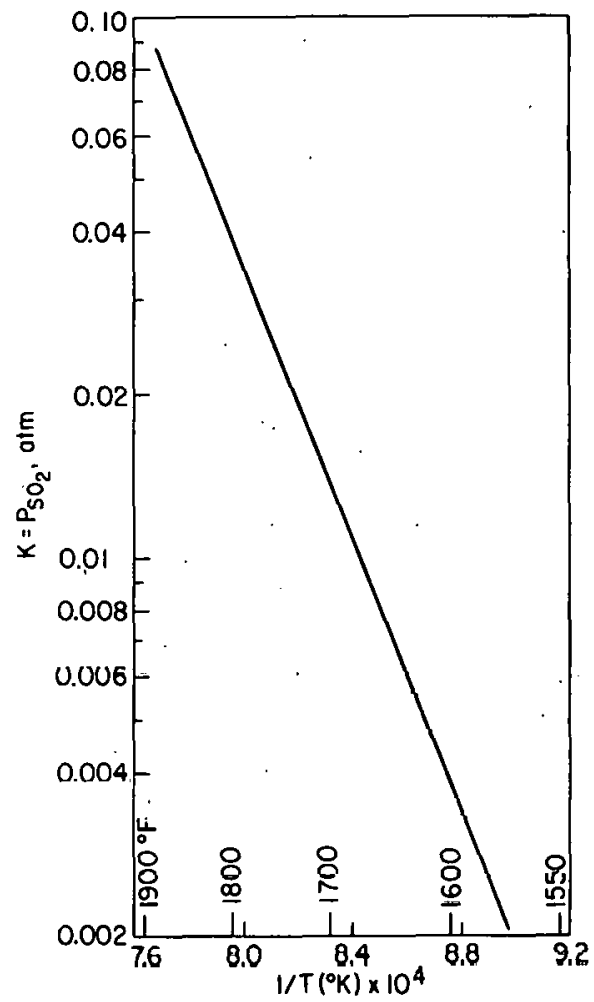

Fig. 19. Equilibrium for the Equation $3 / 4 \mathrm{CaSO}_{4}+$ $1 / 4 \mathrm{CaS}=\mathrm{CaO}+\mathrm{SO}_{2}\left(\right.$ after Zawadzki $^{7}$

coal, in either volatile or particulate form, and to differentiate between volatile and particulate species. It is desirable to identify the compound form and amount of particulate species and to determine the amount and form on condensable species.

Letailed design and engineering drawings of the laboratory-scale batch unit combustor have been completed. The conceptual design of the combustor was presented in a previous report. ${ }^{4}$ The drawings are being checked and reviewed. A work project for fabrication has been established. The fabrication specification for the combustor has heen written, and a final design/preliminary safety review of the combustor is being arranged.

The multiprobe thermocouples required for temperature measurements of the entire system were received. All other components and materials necded for construction of this combustor have already been ordered.

Installation of the induction heating unit is continuing. The work includes the installation of a Tocco $30-\mathrm{kW}$ generator and the installation of working and control stations. About $95 \%$ of the electrical work has been finished. Installation of the water piping required for the cooling system of the unit will be the final part of this job. 
Systematic Study of the Volatility of Trace Elements in Coal

Knowledge of the vaporization characteristics of trace elements in coal and of the rate of their volatilization is important for combined cycle turbine operation. The purpose of this study is to obtain data on the volatility of these elements under practical coal combustion and gasification conditions. This study is also intended to obtain data supporting the study covered above.

The experimental setup for this study was presented previously. ${ }^{4}$ Work on the electricity and water supplies required for the experimental work has been completed. All materials and components ordered have been received, and setting up of the experimental apparatus is under way. 
PROPERTIES OF A DOLOMITE BED OF A RANGE OF

PARTICLE SIZES AND SHAPES AT MINIMUM FLUIDIZATION

\section{Examination of Earlier Experimental Results}

In a previous report, ${ }^{4}$ the results of a series of seven fluidization experiments performed in the ANL 6-in.-dia, fluidized-bed reactor on partially sulfated dolomite particles of a wide range of sizes (about 1410-88 $\mu \mathrm{m}$ ) and shapes were described. The experimental pressure drop $(\Delta P)$ data as a function of fluidizing, velocity (u) were interpreted to determine: the minimum fluidizing velocity ( $u_{m f}$ ) as a function of bed temperature $(T)$ and reactor pressure $(P)$, the height of the bed at minimum fluidization ( $\left.\mathrm{L}_{\mathrm{mf}}\right)$, the mean bed void fraction or voidage at minimum fluidization $\left(\varepsilon_{\mathrm{mf}}\right)$, and the mean shape factor or sphericity of the solid particles consituting the bed $\left(\bar{\phi}_{S}\right)$. In that earlier work, the minimum fluidization velocity was found to be almost independent of bed temperature between 21 and $432^{\circ} \mathrm{C}\left(70-810^{\circ} \mathrm{F}\right)$, bul IL was found to decrease with increasing reactor pressure (26-121 psia) at a given Lemperature. The minimum fluidization velocities were correlated on the basis of the Ergun relation. 10 The correlations of Wen and Yu, 11 Andersson, 12 and Zenz and Othmer ${ }^{13}$ were also examined with appropriate modifications for their applicability to a bed consisting of a wide range of particle sizes and shapes.

The results of the seven fluidization experiments are summarized in Table 10; column 6 lists the previously reported ${ }^{4}$ values of the minimum fluidization velocities, $u_{m f}$. This table lists the values of the particle Reynolds number at minimum fluidization, $R_{p}, \mathrm{mf}$, computed from the following relation:

$$
\operatorname{Re}_{\mathrm{p}, \mathrm{mf}}=\frac{\overline{\mathrm{d}}_{\mathrm{p}} \rho_{\mathrm{g}} \mathrm{u}_{\mathrm{mf}}}{\mu^{1}}
$$

Ilere, $\overline{\mathrm{d}}_{\dot{\mathrm{p}}}$ is the averagc particle diameter, which has a value of $717 \mathrm{\mu m}$ for the dolomite sample used in these experiments; $\rho \mathrm{g}$ and $\mu$ are the density and viscosity of the fluidizing gas, respectively.

The Ergun rorrelation has the following form:

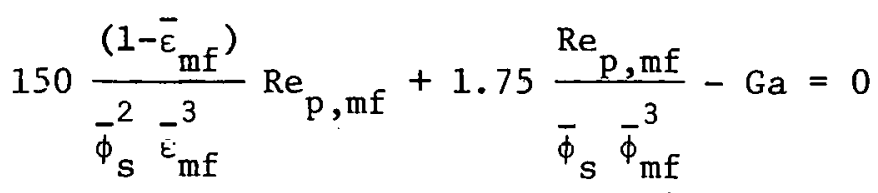

where

$$
G a=\frac{\bar{d}_{p}^{3} \rho_{g}\left(\rho_{s}-\rho_{g}\right) g}{\mu^{2}}
$$


Table 10. Calculation of Mean Sphericity of the Solid Particles, $\bar{\phi}_{S}$, and Correlation of Minimum Fluidization Velocity Data

Equipment: ANL 6-in.-dia combustor

Bed charge: $14.005 \mathrm{~kg}$ of partially sulfated dolomite Fluidizing gas: air

\begin{tabular}{ccccccc}
\hline $\begin{array}{c}\text { Experiment } \\
\text { No. }\end{array}$ & $\begin{array}{c}\text { Temp, } \\
\text { OC }\end{array}$ & $\begin{array}{c}\text { Pressure, } \\
\text { atm }\end{array}$ & $\operatorname{Re}_{\mathrm{p}, \mathrm{mf}}$ & $\bar{\phi}_{\mathrm{s}}$ & \multicolumn{2}{c}{$\mathrm{u}_{\mathrm{mf}}, \mathrm{cm} / \mathrm{sec}$} \\
\hline 2 & 20 & 2.04 & 36 & 0.388 & 36.0 & $38.1(5.7)^{\mathrm{a}}$ \\
3 & 20 & 8.23 & 92 & 0.338 & 23.0 & $25.2(9.6)^{\mathrm{a}}$ \\
4 & 20 & 4.90 & 70 & 0.360 & 27.7 & $30.0(8.2)^{\mathrm{a}}$ \\
5 & $265 \pm 5$ & 1.77 & 12 & 0.452 & 36.0 & $33.5(6.9)^{\mathrm{a}}$ \\
6 & $240 \pm 15$ & 8.16 & 33 & 0.355 & 23.5 & $26.4(12.3)^{\mathrm{a}}$ \\
7 & $380 \pm 30$ & 8.16 & 23 & 0.403 & 23.3 & $25.4(8.8)^{\mathrm{a}}$ \\
8 & $425 \pm 15$ & 4.97 & 14 & $\underline{0.359}$ & 25.9 & $25.8(0.4)^{\mathrm{a}}$ \\
Mean & & &. & 0.379 & &
\end{tabular}

a Percentage difference of calculated and experimental values of $u_{m f}$.

Here, $\bar{\varepsilon}_{\mathrm{mf}}$ is the mean bed void fraction at minimum fluidization; its value was experimentally determined to be $0.65 .4 \mathrm{Also}, \bar{\phi}_{s}$ is the mean shape factor or sphericity of the solid particles, $\mathrm{Ga}$ is the Galileo number, $\rho_{s}$ is the density of the solid particles, and $g$ is the acceleration due to gravity. From the pressure drop measurements at minimum fluidization for the experimental conditions of experiments 5 and 8 , for which $R_{p}, \mathrm{mf}$ is less than 20 and the second term of equation 2 may be ${ }_{4}$ regarded as negligibly sma11, $\bar{\phi}_{\mathrm{S}}$ was earlier determined to be 0.364 .

Here, $\bar{\phi}_{S}$ has been computed from the entire equation 2 for all seven experimental runs. These results are given in the fifth column of Table 10. We take the mean value of 0.379 to be a representative value for the sphericity of the range of solid particles constituting the bed. We checked this by computing the $u_{\mathrm{mf}}$ values from equation 2 for all experiments, using a value of 0.379 for $\bar{\phi}_{S}$, and (as seen from column 7 , Table 10) these values are in good agreement with the directly measured values given in column 6 of Table 10. In the seventh column, in parentheses, are listed the percentage disagreements between the experimental and calculated $u_{m f}$ values. This good agreement substantiates the concept of mean sphericity for the solid particles of a size range constituting the fluidized bed and its adequacy for correlating the minimum fluidization velocity data through the Ergun correlation. It may further be emphasized that the currently determined $\bar{\phi}_{s}$ value differs by less than $4 \%$ from the earlier value so that all conclusions based on the earlier $\bar{\phi}_{S}$ value remain valid. 
The following modified correlation of Wen and $\mathrm{Yu}^{11}$ was examined previously by computing the two sides of the relation and noting their departure from equality.

$$
\bar{\varepsilon}_{\mathrm{mf}}^{4.7} \bar{\phi}_{\mathrm{s}}^{2} \mathrm{Ga}=18 \mathrm{Re}{ }_{\mathrm{p}, \mathrm{mf}}+2.70 \bar{\phi}_{\mathrm{s}}^{0.687}\left(\mathrm{Re}_{\mathrm{p}, \mathrm{mf}}\right)^{1.687}
$$

In Table 11, a more straightforward comparison is presented. After equation 4 was employed to calculate $\operatorname{Re}_{\mathrm{p}, \mathrm{mf}}$ using the values of the parameters reported in Table $11, R_{p}$,mf was used to calculate the values of $u_{\mathrm{mf}}$ with equation 2 . In contrast to the earlier calculations, the results of Table 11 shed light on the adequacy of equation 4 to predict $u_{\mathrm{mf}}$. It is clear that the relation of equation 2 is preferable to that of equation 4 since the accuracy of our experimental $u_{\mathrm{mf}}$ values is assessed to be approximately $\pm 5 \%$.

Table 11. Companison of the Expenimertal Values of umf with the Values Calculated from Equation 4

$$
\left(\overline{\mathrm{d}}_{\mathrm{p}}=720 \mu \mathrm{m}, \bar{\phi}_{\mathrm{s}}=0.364, \bar{\varepsilon}_{\mathrm{mf}}=0.650\right)
$$

\begin{tabular}{ccccc}
\hline $\begin{array}{c}\text { Experiment } \\
\text { No. }\end{array}$ & \multicolumn{2}{c}{$\mathrm{u}_{\mathrm{mf}}, \mathrm{cm} / \mathrm{sec}$} & $\begin{array}{c}\text { Dev., } \\
\%\end{array}$ & $\mathrm{Ga}$ \\
\cline { 2 - 5 } & Expt. & Calc., Eq. 4 & 6.0 & 75895 \\
3 & 36.0 & 38.2 & 16.5 & 300959 \\
4 & 23.0 & 26.7 & 15.6 & 188374 \\
5 & 27.7 & 32.0 & 25.3 & 16506 \\
6 & 36.0 & 45.1 & 19.5 & 70795 \\
7 & 23.5 & 28.1 & 1.6 .3 & 41.961 \\
8 & 23.3 & 27.1 & 11.9 & 22317 \\
\hline
\end{tabular}

\section{Properties of Unreacted-Dolomite Bed at Minimum Fluidization}

A series of eight fluidization experiments were performed earlier on a sample of fresh dolomite. ${ }^{4}$ These results are reported here with a view to investigating the validity of the conclusions presented earlier ${ }^{4}$ and in Tables 10 and 11 .

The reactor was charged with $14.786 \mathrm{~kg}$ of fresh dolomite having the particle size distribution given in column 3, Table 12. After completion of the eight runs, only $11.355 \mathrm{~kg}$ of the material was found in the reactor and $2.955 \mathrm{~kg}$ in the cyclones. Thus, about $3 \%$ of the material was not accounted for; a part of it had been entrained in the gas stream. On the other hand, about $23.2 \%$ of the bed, comprising the fines, was rapidly blown off. The final bed was found to have the 
Table 12. Particle-Size Distribution of Fresh Dolomite Bed Material Before and After the Series C Runs

\begin{tabular}{cccc}
\hline U.S. Sieve No. & $\begin{array}{c}\text { Size Range, } \\
\mathrm{mm}\end{array}$ & \multicolumn{2}{c}{ Weight Fraction in the Range } \\
\cline { 2 - 4 }+14 & $>1.41$ & 0.0000 & After \\
$-14+16$ & $1.41-1.19$ & 0.0241 & 0.0000 \\
$-16+18$ & $1.19-1.00$ & 0.1478 & 0.0224 \\
$-18+20$ & $1.00-0.84$ & 0.1688 & 0.1756 \\
$-20+30$ & $0.84-0.59$ & 0.4067 & 0.2410 \\
$-30+35$ & $0.59-0.50$ & 0.0881 & 0.4449 \\
$-35+45$ & $0.50-0.35$ & 0.1478 & 0.0527 \\
$-45+80$ & $0.35-0.177$ & 0.0105 & 0.0634 \\
$-80+170$ & $0.177-0.088$ & 0.0000 & 0.0000 \\
-170 & $<0.088$ & 0.0073 & 0.0000 \\
Average Particle Diameter, $\mathrm{mm}$ & 650 & 0.0000 \\
\hline
\end{tabular}

particle size distribution given in the fourth column of Table 12; the weight of the remaining bed corresponded to a pressure drop of 0.955 psi. The experiments confirmed this value. Consequently, this pressure drop value was employed in the correlations in determining $u_{\mathrm{mf}}$ from pressure drop data and an average particle diameter value $\left(\bar{d}_{p}\right)$ of $765 \mu \mathrm{m}$. The experimentally determined $u_{m f}$ values from the measurements of pressure drop as a function of the fluidizing velocity (u) are given in the fourth column of Table 13 for the operating conditions of temperature and pressure in columns 2 and 3 , respectively. The first four runs ( $C-1$ through $\mathrm{C}-4$ ), performed at room temperature, are considered more reliable than the ones performed at higher temperatures and are therefore the only ones employed in determining the average sphericity of the solid bed particles.

The Ergun correlation at minimum fluidization is: $:^{1.4}$

$$
\frac{\Delta \mathrm{P}_{\mathrm{mf}} \mathrm{g}_{\mathrm{c}}}{\mathrm{L}_{\mathrm{mf}}}=150 \frac{\left(1-\bar{\varepsilon}_{\mathrm{mf}}\right)^{2} \mu \mathrm{u}_{\mathrm{mf}}}{\bar{\Xi}_{\mathrm{mf}}^{3}\left(\bar{\phi}_{\mathrm{s}} \overline{\mathrm{d}}_{\mathrm{p}}\right)^{2}}+1.75 \frac{\left(1-\bar{\varepsilon}_{\mathrm{mf}}\right) \rho_{\mathrm{g}} \mathrm{u}_{\mathrm{m}}^{2}}{\bar{\varepsilon}_{\mathrm{mf}}^{3}\left(\bar{\phi}_{\mathrm{s}} \overline{\mathrm{d}}_{\mathrm{p}}\right)}
$$

Further,

$$
\Delta \mathrm{P}_{\mathrm{mf}} \mathrm{g}_{\mathrm{c}}=\left(\rho_{\mathrm{s}}-\rho_{\mathrm{g}}\right)\left(1-\bar{\varepsilon}_{\mathrm{mf}}\right) \mathrm{L}_{\mathrm{mf}} \mathrm{g}
$$

Here $\Delta \mathrm{P}_{\mathrm{mf}}$ is the pressure drop across a bed of height $\mathrm{L}_{\mathrm{mf}}, \mathrm{g}_{\mathrm{c}}$ is the conversion factor and is equal to $980 \mathrm{~g} \mathrm{~cm} /(\mathrm{g} \mathrm{wt})\left(\mathrm{sec}^{2}\right), \mu$ is the gas viscosity, $\rho_{\mathrm{g}}$ is the gas density, $\rho_{\mathrm{s}}$ is the solid particle density, and $g$ is the acceleration due to gravity. The relation given in equation 6 , in conjunction with the experimentally measured $\Delta \mathrm{P}_{\mathrm{mf}}$ values, lead to 
Table 13. Values of $\mathrm{u}_{\mathrm{mf}}, \mathrm{L}_{\mathrm{mf}}, \bar{\varepsilon}_{\mathrm{mf}}, \mathrm{Re}_{\mathrm{p}, \mathrm{mf}}$, and $\bar{\phi}_{\mathrm{s}}$ at Various Temperatures and Pressures

\begin{tabular}{cccccccc}
\hline $\begin{array}{c}\text { Experiment } \\
\text { No. }\end{array}$ & $\begin{array}{r}\text { Temp, } \\
{ }^{\circ} \mathrm{F}\end{array}$ & $\begin{array}{c}\text { Pressure, } \\
\mathrm{psia}\end{array}$ & $\begin{array}{c}\mathrm{u}_{\mathrm{mf}}, \\
\mathrm{ft} / \mathrm{sec}\end{array}$ & $\begin{array}{c}\mathrm{L}_{\mathrm{mf}}, \\
\mathrm{ft}\end{array}$ & $\bar{\varepsilon}_{\mathrm{mf}}$, & $\mathrm{Re}_{\mathrm{p}, \mathrm{mf}}$ & $\bar{\phi}_{\mathrm{S}}$ \\
$\mathrm{C}-1$ & 65 & 27 & 1.38 & 2.03 & 0.55 & 39 & 0.570 \\
$\mathrm{C}-2$ & 65 & 60 & 1.13 & 2.02 & 0.56 & 72 & 0.568 \\
$\mathrm{C}-3$ & 65 & 93 & 0.94 & 2.00 & 0.58 & 91 & 0.503 \\
$\mathrm{C}-4$ & 65 & 120 & 0.82 & 1.94 & 0.59 & 102 & 0.452 \\
$\mathrm{C}-5$ & $690 \pm 25$ & 19 & 1.24 & 2.02 & 0.59 & 6.2 & -- \\
$\mathrm{C}-6$ & $555 \pm 15$ & 57 & 1.19 & 1.78 & 0.54 & 22 & -- \\
$\mathrm{C}-7$ & $465 \pm 5$ & 87 & 1.04 & 1.72 & 0.55 & 34 & -- \\
$\mathrm{C}-8$ & $395 \pm 15$ & 121 & 0.94 & 1.63 & $\underline{0.56}$ & 50 & -- \\
Mean & & & & & 0.57 & & 0.52 \\
\hline
\end{tabular}

$\bar{\varepsilon}_{\mathrm{mf}}$ values for eight experiments that are listed in column 6 of Table 13 . A mean value of 0.57 for $\bar{\varepsilon}_{\mathrm{mf}}$ was employed in all calculations reported here.

Thus with a known $\bar{\varepsilon}_{\mathrm{mf}}$, equation 5 was used to compute $\bar{\phi}_{\mathrm{S}}$ for exper1ments $\mathrm{C}-1$ through $\mathrm{C}-4$. The results are given In lie. elghli culum uf Table 13. A mean value of 0.52 for $\bar{\phi}_{s}$ was used throughout this work. Computed values of Reynolds number, Re , mf, from the following relation are given in column 7 of Table 13:

$$
\operatorname{Re}_{\mathrm{p}, \mathrm{mf}}=\frac{\overline{\mathrm{d}}_{\mathrm{p}} \rho_{\mathrm{g}} \mathrm{u}_{\mathrm{mf}}}{\mu}
$$


SEPARATION OF COMBUSTION AND REGENERATION SYSTEMS

As originally installed, the 6-in.-dia, pressurized, fluidized-bed combustor and the 3-in.-dia, pressurized, fluidized-bed regenerator utilized several components in common. Due to the dual function of these components, the two units could not be operated simultaneously. The equipment common to both units included the inlet and outlet surge tanks, the gas preheater, the additive solids-feeder, the off-gas system (cyclones, filters, pressure-control valve, etc.), and the offgas analysis system.

Modifications of both systems were undertaken to physically separate the two units and to provide each unit with its own ancillary equipment. The objective of the modifications is to permit concurrent investigations of the combustion process and the regeneration process, thereby increasing the capability for research relating to both processes.

The current status of the more significant items involved in the modifications is presented below:

1. Alterations to the combustion system equipment were completed and installation of the new regeneration system is nearly complete.

2. A new rotary-vane solids-feeder was delivered, leaving the off-gas conditioning system and the gas preheater as the only two major components for the new regeneration system still to be received. Delivery of these two items is expected in the near future; other available equipment has been substituted and installed pending delivery to permit testing of the new regeneration system.

3. Installation of the necessary pneumatic and electrical process and instrument services for the new regeneration system has been essentially completed. Only a minor amount of work remains to complete the final hookup of these services.

4. Provisions were made for feeding both coal and sulfated additive into the new regeneration system. (The coal, combusted under reducing conditions, will supply both the reducing gases and the heat required for one-step reductive decomposition of the sulfated additive.) Installation of the necessary feeding equipment for the coal and additive (scales, solids-feeders, feed-hoppers, etc.) was completed, and testing of the equipment is in progress.

5. Installation of the necessary sheet-metal ducts for venting the regeneration enclosure and associated equipment into the existing laboratory main ventilation system was begun and is expected to be completed in a few weeks.

6. Installation and calibration of the analytical instruments to be used for determining $\mathrm{O}_{2}, \mathrm{SO}_{2}, \mathrm{CO}, \mathrm{CO}_{2}, \mathrm{H}_{2}, \mathrm{H}_{2} \mathrm{~S}$, total hydrocarbons, NO- $\mathrm{NO}_{x}$, and $\mathrm{H}_{2} \mathrm{O}$ concentrations in the regenerator of $f$ gas have been completed except for minor revisions and operational testing. 
REFERENCES

1. H. D. Levene and J. W. Hand, "Sulfur Stays in the Ash When Lignite Burns," Coal Min. Process. 12(2), 46-48 (February 1975).

2. G. J. Vogel et al., "Reduction of Atmospheric Pollution by the Application of Fluidized-Bed Combustion and Regeneration of SulfurContaining Additives," Annual Report, July 1973 - June 1974, Argonne National Laboratory, ANL/ES/CEN-1007 (1974).

3. A. A. Jonke et $a Z$., "Reduction of Atmospheric Pollution by the Application of Fluidized-Bed Combustion," Annual Report, July 1969 June 1970, Argonne National Laboratory, ANL/ES/CEN-1002 (1970).

4. G. J. Vogel, "A Development Program on Pressurized Fluidized-Bed Combustion," Annual Report, July 1974 - June 1975, Argonne Nationa1 Laboratory, ANL/ES-CEN-1011 (in print).

5. R. T. Yang, P. T. Cunningham, W. I. Wilson, and S. A. Johnson, "Sulfur Removal and Recovery from Industrial Processes," Advan. Chem., Series 137, pp. 149-157 (1974).

6. G. P. Curran et al., "Phase II: Bench Scale Research on CSG Process, Operation of the Bench Scale Continuous Gasification Unit," Consolidation Coa1 Co. R\&D Report No. 16, Dec. 1, 1965 to July 1, 1968, p. 190 .

7. J. Zawadzki, Wur Kenntnis des Systems Calcium-Schiwnefel-Sauerstoff, 2. Anorg. Allg. Chem., Band 2US, I8U-192 (19932).

8. G. P. Curran et al., Phase II: Bench Scale Research on CSG Process. Operation of the Bench Scale Continusus Gasifiratinn Init, Consolidation Coal Co. R\&D Report No. 16, Dec. 1, 1967 to July 1, 1968, p. 188 .

9. G, J, Vogel et al., "Reduction of Atmospheric Pollution by the Application of Fluidized-Bed Combustion," Annual Report, July 1972June 1973, Ȧrgonne National Laboratory, ANL/ES-CEN=1006 (1974).

10. S. Ergun, Chem. Éng. Progr. 48, 89-94 (1952).

11. C. Y. Wen and Y. H. Yu, Chem, Eng. Progr. Symp. Ser. 62, No. 62, 100-1.1 (1966).

12. K. E. Bertil Andersson, Chem. Eng. Sci. 15, 276-97 (1971).

13. F. A. Zenz and D. F. Othmer, Fluidization and Fluid-Particle Systems, Ch. 7, Relnhold Publishing Corporac1on, New York (1960).

14. D. Kunii and 0 . Levenspiel, Fluidization Engineering, Ch. 3, John Wiley \& Sons, Inc., New York (1969). 